\title{
The phylogenetic affinities of the bizarre Late Cretaceous Romanian theropod Balaur bondoc (Dinosauria, Maniraptora): dromaeosaurid or flightless bird?
}

Andrea Cau, Tom Brougham, Darren Naish

The exceptionally well-preserved Romanian dinosaur Balaur bondoc is the most complete theropod known to date from the Upper Cretaceous of Europe. Previous studies of this remarkable taxon have included its phylogenetic interpretation as an aberrant dromaeosaurid with velociraptorine affinities. However, Balaur displays a combination of both apparently plesiomorphic and derived bird-like characters. Here, we analyse those features in a phylogenetic revision and show how they challenge its referral to Dromaeosauridae. Our reanalysis of two distinct phylogenetic datasets focusing on basal paravian taxa supports the reinterpretation of Balaur as an avialan more crownward than Archaeopteryx but outside of Pygostylia, and as a flightless taxon within a paraphyletic assemblage of long-tailed birds. Our placement of Balaur within Avialae is not biased by character weighting. The placement among dromaeosaurids resulted in a suboptimal alternative that cannot be rejected based on the data to hand. Interpreted as a dromaeosaurid, Balaur has been assumed to be hypercarnivorous and predatory, exhibiting a peculiar morphology influenced by island endemism. However, a dromaeosaurid-like ecology is contradicted by several details of Balaur's morphology, including the loss of a third functional manual digit, the non-ginglymoid distal end of metatarsal II, and a non-falciform ungual on the second pedal digit that lacks a prominent flexor tubercle. Conversely, an omnivorous ecology is better supported by Balaur's morphology and is consistent with its phylogenetic placement within Avialae. Our reinterpretation of Balaur implies that a superficially dromaeosaurid-like taxon represents the enlarged, terrestrialised descendant of smaller and probably volant ancestors. 
2 The phylogenetic affinities of the bizarre Late Cretaceous Romanian theropod Balaur bondoc (Dinosauria, Maniraptora): dromaeosaurid or flightless

4 bird?

6 Andrea $\mathrm{Cau}^{1 *}$, Tom Brougham ${ }^{2,3}$, Darren Naish ${ }^{2,3}$

$7 \quad{ }^{1}$ Earth, Life and Environmental Sciences Department, Alma Mater Studiorum, Bologna

8 University, Italy; email: cauand@gmail.com;

$9{ }^{2}$ Ocean and Earth Science, University of Southampton, Southampton SO14 3ZH, UK; emails:

10 tbrougham@paravian.net, eotyrannus@gmail.com

$11{ }^{3}$ These authors contributed equally

$12 *$ Corresponding author

13

14 
15 The theropod dinosaur Balaur bondoc from the Maastrichtian (latest Late Cretaceous) of

16 Romania represents the most complete theropod dinosaur yet known from the Upper Cretaceous

17 of Europe (Csiki et al. 2010). The remarkably well-preserved holotype specimen of B. bondoc,

18 EME (Transylvanian Museum Society, Dept. of Natural Sciences, Cluj-Napoca, Romania)

19 PV.313, was collected from red overbank floodplain sediments of the Maastrichtian Sebeş

20 Formation in 2009 and comprises an articulated partial postcranial skeleton of a single

21 individual, including dorsal, sacral and caudal vertebrae as well as much of the pectoral and

22 pelvic girdles and limbs (Brusatte et al. 2013). The first phylogenetic studies incorporating

23 Balaur concluded that it represents an aberrant dromaeosaurid with velociraptorine affinities,

24 endemic to the European palaeoislands of the Late Cretaceous (Csiki et al. 2010; Turner et al.

25 2012; Brusatte et al. 2013). The matrices utilised in these three studies have all been versions of

26 the Theropod Working Group (TWiG) matrix, an incrementally and independently developed

27 large-scale matrix focusing on the interrelationships of coelurosaurian taxa (e.g., Norell et al.

28 2001; Makovicky et al. 2005; Turner et al. 2007; Turner et al. 2012; Brusatte et al. 2014).

29 Comparison made between Balaur and other dromaeosaurids reveals the possession of a suite of

30 autapomorphies not present in dromaeosaurids nor in most other non-avialan theropods, such as

31 a fused carpometacarpus, loss of a functional third manual digit, proximal fusion of the

32 tarsometatarsus, and a relatively enlarged first pedal digit (Csiki et al. 2010; Brusatte et al. 2013).

33 Interpreted as a dromaeosaurid, Balaur is a strikingly odd and apparently avialan-like taxon.

34 Recently, Godefroit et al. (2013a) included Balaur in a new phylogenetic analysis focusing on

35 paravians and found it resolved as a basal avialan, more crownward than Archaeopteryx. A

36 similar result was obtained independently by Foth et al. (2014) using a dataset expanded from

37 that of Turner et al. (2012): Foth et al. (2014) recovered Balaur in a position relatively less

38 crownward than in the tree obtained by Godefroit et al. (2013a), but still crownward of

39 Archaeopteryx. The present study focuses on resolving these conflicting interpretations regarding

40 the affinities of Balaur following examination of the holotype material (performed by TB and

41 DN). We also present a revised phylogenetic hypothesis based on a comparison of updated

42 versions of previously published taxon-character matrices.

43 Materials and methods

44 In order to test the competing dromaeosaurid and avialan hypotheses for the affinities of Balaur,

45 we coded the holotype specimen into modified versions of two recently published theropod 
46 phylogenetic matrices: Brusatte et al. (2014) and Lee et al. (2014). Both of these large-scale and 47 independently coded matrices focused on the interrelationships of theropod dinosaurs and 48 contain a broadly overlapping and comprehensive sampling of over 100 theropod taxa (152 and 49120 taxa respectively), including many basal avialans. The two matrices differ from each other in 50 the logical basis on character statement definitions (Sereno 2007; Brazeau 2011, see discussion 51 below).

52 Brusatte et al. (2014) data set

53 The dataset used by Brusatte et al. (2014) is an updated version of the dataset of Turner et al. 54 (2012). We modified the Brusatte et al. (2014) matrix for this study to include seven new 55 56 57 58 characters and updated character states for three previously defined characters (see Electronic Supplementary Material). All character statements considered to be ordered by Brusatte et al.

57 (2014) were set accordingly. The resulting data matrix (860 characters vs 152 taxa) was then 8 analysed using the Hennig Society version of TNT v1.1 (Goloboff et al. 2008b; see Electronic 9 Supplementary Material for further details regarding modifications to the matrix and tree search 60 strategy).

Lee et al. (2014) data set

62 The dataset used by Lee at al. (2014) is an updated version of the dataset of Godefroit et al.

63 (2013a). Character statements of the 1549 included characters and the source of scores for the 64 included 120 fossil taxa are stored at the Dryad Digital Repository (Cau et al. 2014). In our 65 study, this dataset has been expanded to including an additional taxonomic unit based on the extant avian Meleagris (ACUB 4817); accordingly, character statement 318 has been modified

67 (see Electronic Supplementary Material). Balaur was re-scored based on our examination of the 68 specimen and the incorporation of information from Brusatte et al. (2013). Lee et al. (2014) 69 applied Bayesian inference in their analysis of this dataset and integrating the morphological information with chronostratigrafic information. In the present study, the updated morphological 71 data matrix (1549 characters vs 121 taxa) was analysed using parsimony as the tree search 72 strategy in TNT (see Electronic Supplementary Material).

73 Alternative placement test and implied weighting analyses

74 In our analyses of both datasets, we constrained the alternative deinonychosaurian and avialan 75 positions for Balaur, measuring step changes between resultant topologies as a further indication 
76 of their relative support. Templeton's test (Templeton 1983) was used to determine whether the

77 step differences between the unforced and forced topologies were statistically significant. The

78 backbone constraints used the following species: a crown avian (Anas platyrhynchus in the

79 dataset of Brusatte et al. 2014, Meleagris gallopavo in the dataset of Lee et al. 2014), a

80 dromaeosaurid (Dromaeosaurus albertensis in both datasets), and a troodontid (Troodon

81 formosus in both datasets).

82 In order to test whether assumptions on downweighting of homoplasious characters influence the

83 placement of Balaur among Paraves, both datasets were subjected to implied weighting analyses

84 (IWAs, Goloboff 1993, Goloboff et al. 2008a, b; see Electronic Supplementary Material).

85 Institutional abbreviations

$86 A C U B$, Museo di Anatomia Comparata, University of Bologna, Bologna, Italy. EME,

87 Transylvanian Museum Society, Dept. of Natural Sciences, Cluj-Napoca, Romania.

88 Comparative anatomy of Balaur and other maniraptoran theropods

89 Compared to other theropods, Balaur displays a unique and unexpected combination of

90 characters (Brusatte et al. 2013). The phylogenetic analyses of Csiki et al. (2010) and Turner et

91 al. (2012) resolved Balaur as a velociraptorine dromaeosaurid. Consequently, most of the

92 unusual characters shared by Balaur with non-dromaeosaurid theropods were interpreted as

93 autapomorphies, independently evolved along the lineage leading exclusively to Balaur. An

94 alternative explanation is that these features may indicate a closer relationship between Balaur

95 and another non-dromaeosaurid clade of maniraptorans. Here, we list the most relevant

96 characters that may support or challenge the alternative placements of Balaur within

97 Maniraptora.

98

99

100

101

104

102 Chiappe et al. 1999; Agnolín and Novas 2013).

103 Sacrum including at least seven fused vertebrae

Dorsal vertebrae with stalked parapophyses

The dorsal vertebrae of Balaur bear distinctly stalked parapophyses (Brusatte et al. 2013).

Although this feature has been reported as a deinonychosaurian synapomorphy (Turner et al.

2012), stalked parapophyses are also present in alvarezsaurids and basal avialans (Novas 1997;

The presence of five fused sacral vertebrae is the plesiomorphic condition within coelurosaurs 
105 (e.g., Brochu 2003). An independent increase in the number of fused sacral vertebrae is a 106 widespread phenomenon within Maniraptoriformes. Six to seven sacral vertebrae are present in 107 ornithomimids (Osmólska et al. 1972), Late Cretaceous oviraptorosaurs (Barsbold et al. 2000),

108 and some dromaeosaurids (Norell and Makovicky 1997; Turner et al. 2012; S. Brusatte pers.

109 comm. 2014). The synsacrum is composed of seven vertebrae in parvicursorine alvarezsauroids,

110 whereas in basal taxa it includes only five vertebrae (Choiniere et al. 2010). Archaeopteryx and

111 basal paravians retain five sacral vertebrae (Hwang et al. 2002; Paul 2002; Godefroit et al.

112 2013b; Godefroit et al. 2013a), whereas a sacrum with at least seven vertebrae has been regarded

113 as a synapomorphy of Jixiangornis and pygostylians (Turner et al. 2012). Balaur has at least

114 seven sacral vertebrae: four fused and clearly discernible sacral vertebrae bearing sacral ribs are

115 followed by three additional and co-ossified caudosacrals (Brusatte et al. 2013).

116 Fused scapulocoracoid

117 In Balaur, the scapula and coracoid are co-ossified and the suture is obliterated on both sides

118 (Fig. 1a; Brusatte et al. 2013). Brusatte et al. (2013) noted that a fused scapulocoracoid is present

119 in some dromaeosaurids (e.g., Adasaurus, Microraptor, Velociraptor; see Fig. 1c) but not in

120 others (e.g., Achillobator, Buitreraptor, Deinonychus, Sinornithosaurus, Unenlagia). Turner et

121 al. (2012) included fusion of the scapulocoracoid among the phylogenetically informative

122 characters of their paravian phylogeny. Within non-avialan coelurosaurs, the presence of this

123 character state has been reported within ornithomimosaurs, therizinosauroids, alvarezsauroids,

124 tyrannosaurids and oviraptorosaurs (Osmólska et al. 1972; Perle 1979; Perle et al. 1994; Brochu

125 2003; Balanoff and Norell 2012), suggesting a high degree of homoplasy. Fusion of the

126 scapulocoracoid is also present in basal avialans (e.g., Confuciusornithidae; Chiappe et al. 1999)

127 and flightless avians (e.g., Struthio; ACUB 4820).

128 Coracoid with prominent tuber placed on the anterolateral corner

129 The coracoid of Balaur bears a hypertrophied tubercle that forms the anterolateral corner of the

130 bone and obscures the supracoracoid nerve foramen when the coracoid is observed in lateral

131 view (Fig. 1a; Brusatte et al. 2013). Non-avialan theropods possess tubercles that are relatively

132 smaller and more lateroventrally directed (when the scapula is oriented horizontally) than that

133 seen in avialan theropods (Fig. 1c; Osmólska et al. 1972; Ostrom 1976; this is the "processus

134 praeglenoidalis" sensu Elzanowski et al. 2002). Although the coracoid tubercle of Balaur may 
135 appear autapomorphic among non-avialan theropods (Brusatte et al. 2013), a prominent coracoid 136 tubercle is also present in unenlagiines (Buitreraptor, see Agnolin and Novas 2013), basal

137 avialans (e.g., Jeholornis, Jixiangornis; Turner et al. 2012, fig. 82), and forms the acrocoracoid

138 of ornithothoracines (e.g., Apsaravis, Enantiophoenix, Enantiornis; Clarke and Norell 2002;

139 Baier et al. 2007; Cau and Arduini 2008; Walker and Dyke 2009; Fig. 1). A hypertrophied

140 coracoid tubercle that obscures the supracoracoid nerve foramen in lateral view is also seen in

141 Sapeornis (Zhou and Zhang 2003; Gao et al. 2012).

142 Humerus longer than half the combined length of tibiotarsus and tarsometatarsus

143 The ratio between the lengths of the humerus and femur is usually considered as a

144 phylogenetically informative character in discussions on the evolution of coelurosaurian

145 theropods (e.g., Brusatte et al. 2014, character 262), as that ratio is usually higher among

146 avialans than it is in most non-avialan theropods. Since the femur of Balaur is unknown

147 (Brusatte et al. 2013), we used the ratio between the length of the humerus and the sum of the

148 lengths of the tibiotarsus and tarsometatarsus. The humerus of non-avialan theropods is

149 consistently shorter than half the combined length of the tibiotarsus and tarsometatarsus (e.g.,

150 Deinonychus, Gallimimus, Microraptor, Tyrannosaurus; Ostrom 1969; Osmólska et al. 1972;

151 Hwang et al. 2002; Brochu 2003). In Balaur, the humerus is longer than half the combined

152 length of the tibiotarsus and tarsometatarsus (55\%) and approaches the condition seen in basal

153 avialans (e.g., Archaeopteryx: 59\%, Confuciusornis: 67\%, Jeholornis: 77\%; Chiappe et al. 1999;

154 Elzanowski 2001; Zhou and Zhang 2002; see Brusatte et al. 2013, table 2). The interpretation of

155 this feature is problematic, since distal hindlimb elongation is not correlated to femur length

156 among theropods (Holtz 1995); accordingly, we have avoided its inclusion among the new

157 characters added to the phylogenetic analyses. We have retained the original humerus/femur

158 ratio characters in both datasets and thus score Balaur as "unknown" for them. Therefore, the

159 results of our analyses are not biased by the use of that character.

160 Humeral condyles placed on the anterior surface of the distal end

161 The humerus of Balaur possesses condyles that are placed entirely on the anterior surface of the

162 bone (Brusatte et al. 2013). As in Balaur, the complete anterior migration of the humeral

163 condyles is present in therizinosauroids (e.g., Zanno 2010), alvarezsauroids (Novas 1997), basal

164 pygostylians (e.g., Confuciusornis, Limenavis, Enantiornis; Chiappe et al. 1999; Clarke and 
165 Chiappe 2001; Walker and Dyke 2009), and extant birds (e.g., Dromaius, Meleagris, Struthio; 166 ACUB 3131; 4817; 4820). All other known dromaeosaurids (e.g., Deinonychus; Ostrom 1969), 167 most non-avialan theropods (e.g., Gallimimus, Allosaurus, Tyrannosaurus; Osmólska et al. 1972; 168 Madsen 1976; Brochu 2003), and early avialans (e.g., Archaeopteryx; Berlin specimen) bear the 169 condyles in a more distal position, with a limited, if not absent, extent onto the anterior surface of 170 the bone. In the analysis of Turner et al. (2012), Balaur was scored as retaining the primitive 171 condition (contra Brusatte et al. 2013, 2014).

172 Deep and elongate triangular brachial fossa on humerus

173 The humerus of Balaur bears a prominent triangular fossa on the anterior surface of the distal 174 end of the humerus (Brusatte et al. 2013, fig. 12). This fossa is bordered both laterally and 175 medially by raised crests confluent with the epicondyles. The same configuration defines the 176 brachial fossa present in pygostylians (e.g., Confuciusornis, Limenavis, Apsaravis; Chiappe et al. 177 1999; Clarke and Chiappe 2001; Clarke and Norell 2002). This fossa is also variably developed 178 within dromaeosaurids (e.g., Bambiraptor; Turner et al. 2012; Brusatte et al. 2013).

179 Ulna with brachial depression

180 The proximal third of Balaur's ulna bears a shallow, elongate depression on the medial surface 181 termed the "proximal fossa" (Brusatte et al. 2013, fig. 14). This character is topographically 182 equivalent to the brachial fossa present in pygostylians (Baumel and Witmer 1993; Clarke and 183 Chiappe 2001; Walker and Dyke 2009). The ulna of most non-avialan theropods lacks a brachial 184 depression or possesses a poorly developed one (e.g., Allosaurus, Tyrannosaurus; Madsen 1976; 185 Brochu 2003). However, the structure is well developed in some dromaeosaurids (e.g.,

186 Bambiraptor, Buitreraptor; Burnham 2004; Agnolín and Novas 2011; Agnolín and Novas 2013).

187 Distal carpals fused to proximal end of metacarpals

188 The manus of Balaur displays co-ossification of the distal carpals with the proximal ends of the 189 metacarpals (Fig. 2a; Brusatte et al. 2013), unlike the dromaeosaurid condition in which no such 190 fusion in present (Fig. 2d). The fusion between the distal carpals and the metacarpals is present 191 in a few non-avialan theropod lineages (e.g., Avimimus, Mononykus; Kurzanov 1981; Perle et al. 192 1993), and in pygostylians (e.g., Confuciusornis, Xiangornis; Chiappe et al. 1999; Hu et al. 193 2012). In particular, the pattern of proximal fusion among the carpometacarpal elements in

194 Balaur is shared by most basal pygostylians (e.g., Confuciusornis, Sinornis, Sapeornis, 
195 Pengornis, Enantiornis, Zhouornis; Chiappe et al. 1999; Sereno et al. 2002; Zhou and Zhang 196 2003; Zhou et al. 2008; Walker and Dyke 2009; Zhang et al. 2013; see Fig. 2b-c, Fig. S1). Most

197 ornithurines and some enantiornithines display complete distal fusion between metacarpals II

198 and III in addition to the aforementioned proximal fusion of the carpometacarpus as seen in

199 Balaur (e.g., Apsaravis, Teviornis, Xiangornis; Clarke and Norell 2002; Kurochkin et al. 2002;

200 Hu et al. 2012).

201 Semilunate carpal shifted laterally and first metacarpal sloped proximolaterally

202 In Balaur, the semilunate carpal overlaps the whole proximal ends of both metacarpals II and III

203 (Fig. 2a, Fig. S1). Furthermore, the proximal end of the first metacarpal in Balaur is

204 mediolaterally narrower than the distal end, producing a proximolaterally sloping medial margin

205 of the metacarpus. In Archaeopteryx and most non-avialan maniraptorans, the proximal end of

206 the first metacarpal is not constricted compared to the distal end, and the semilunate carpal

207 overlaps most of metacarpal I; meanwhile, the overlap on metacarpal III is absent or limited to

208 the medialmost margin of the bone (Fig. 2d; Ostrom 1976, fig. 10; Xu et al. 2014). Therefore, the

209 position of the semilunate carpal of Balaur represents a lateral shift compared to the condition in

210 other non-avialan maniraptorans, and recalls long-tailed and pygostylian birds where the

211 semilunate carpal has a reduced or absent overlap on metacarpal I and extensively covers both

212 metacarpals II and III (e.g., Confuciusornis, Sinornis, Sapeornis, Enantiornis, Zhouornis;

213 Chiappe et al. 1999; Sereno et al. 2002; Zhou and Zhang 2003; Walker and Dyke 2009; Zhang et

214 al. 2013; see also Xu et al. 2014; see Fig. 2b-c). As in Balaur, pygostylian birds show a

215 mediolateral constriction of the proximal end of the first metacarpal, and a medial margin

216 ("anterior margin", using Nomina Anatomica Avium nomenclature, see Harris 2004) that is

217 variably sloped proximolaterally in extensor view.

218 Condyles of metacarpals I-II restricted to the distal and ventral surfaces of the metacarpals

219 Metacarpals I and II of Balaur bear condyles that are restricted to the distal and ventral surfaces

220 of the metacarpals, and are excluded from the extensor surfaces (Brusatte et al. 2013). The

221 dromaeosaurid condition (e.g., Deinonychus, Velociraptor, Graciliraptor; Ostrom 1969; Norell

222 and Makovicky 1999; Xu and Wang 2003), in which the condyles are expanded along the

223 extensor surface of the metacarpals, is present in most non-avialan theropods (e.g.,

224 Acrocanthosaurus, Allosaurus, Australovenator, Berberosaurus, Dilophosaurus, Patagonykus, 
225 Rapator; Madsen 1976; Welles 1984; Novas 1997; Senter and Robins 2005; Allain et al. 2007;

226 White et al. 2013). The condition present in the metacarpals of Balaur is also present in

227 pygostylians (e.g., Teviornis, Sinornis, Enantiornis; Kurochkin et al. 2002; Sereno et al. 2002;

228 Walker and Dyke 2009) and extant avians (e.g., Dromaius; Meleagris, Struthio; ACUB 3131;

229 4817; 4820). Furthermore, the ventral surface of the metacarpals of Balaur are excavated by a

230 wide flexor sulcus but lack distinct flexor pits at the distal end, similar to the condition present in

231 avialans (e.g., Teviornis; Kurochkin et al. 2002) but differing from that of dromaeosaurids and

232 most non-avialan theropods that do bear a distinct flexor pit (e.g., Allosaurus, Acrocanthosaurus,

233 Mahakala, Velociraptor; Madsen 1976; Senter and Robins 2005; Turner et al. 2011).

234 Metacarpal II with an intermetacarpal ridge running along the dorsolateral edge of the bone

235 and closed intermetacarpal space between metacarpals II and III

236 Balaur possesses a distinct web of bone that extends along the dorsolateral edge of metacarpal II

237 and contacts metacarpal III distally, and a distally closed intermetacarpal space between

238 metacarpals II and III (Brusatte et al. 2013). Within basal avialans, the extent of the contact

239 between metacarpals II and III displays some variation, ranging from the close contact of a

240 straight metacarpal III to metacarpal II with no intermetacarpal space (e.g., Sapeornis; Zhou and

241 Zhang 2003; Gao et al. 2012; see Fig. 2, Fig. S1), an appressed distal contact but no fusion of

242 metacarpal III to metacarpal II (the condition as seen in Balaur and many basal avialans,

243 including Jeholornis, Enantiornis, Confuciusornis, Zhouornis, and Piscivoravis; Zhou and Zhang

244 2002; Walker and Dyke 2009; Zhang et al. 2009; Zhang et al. 2013; Zhou et al. 2014), to distal

245 obliteration of the contact between metacarpals II and III due to complete fusion between the

246 bones (e.g., Teviornis, Xiangornis, Meleagris; Kurochkin et al. 2002; Hu et al. 2012; ACUB

247 4817). A closed intermetacarpal space is present in Confuciusornis (Chiappe et al. 1999; Zhang

248 et al. 2009), some long-tailed birds (e.g., Jeholornis, Jixiangornis; Zhou and Zhang 2002), and

249 ornithothoracines (e.g., Enantiornis, Xiangornis, Zhouornis; Walker and Dyke 2009; Hu et al.

250 2012; Zhang et al. 2013; see Fig. 2b). Most euornithines differ from Balaur and most other

251 avialans in having a more distally placed intermetacarpal space relative to a more shortened

252 metacarpal I (e.g., Teviornis; Kurochkin et al. 2002).

253 Distal end of metacarpal III unexpanded and not divided into separated condyles

254 The third metacarpal of Balaur bears a simple distal end that lacks distinct condyles. 
255 Dromaeosaurids share with most non-avialan theropods the presence of well-defined metacarpal 256 condyles separated by an intercondylar sulcus (e.g., Allosaurus, Bambiraptor, Deinocheirus, 257 Deinonychus, Dilophosaurus, Gallimimus; Ostrom 1969; Osmólska and Roniewicz 1970;

258 Osmólska et al. 1972; Madsen 1976; Welles 1984; Burnham 2004). The condition present in the 259 third metacarpal of Balaur is shared by tyrannosaurids (e.g., Tyrannosaurus; Lipkin and 260 Carpenter 2008, fig. 10.10), basal pygostylians (e.g., Confuciusornis, Enantiornis, Sinornis, 261 Teviornis, Xiangornis, Zhouornis; Chiappe et al. 1999; Kurochkin et al. 2002; Sereno et al. 2002; 262 Walker and Dyke 2009; Hu et al. 2012; Zhang et al. 2013) and crown avians (e.g., Meleagris, 263 Struthio; ACUB 4817; 4820). This character is not obviously linked with the reduction in the 264 number of phalanges in digit III (see below), since Confuciusornis shows the derived metacarpal 265 condition (i.e., simple distal end of metacarpal III) yet retains a full set of four functional 266 phalanges in digit III.

267 Third manual digit bearing less than three phalanges

268 The third manual digit of Balaur is extremely reduced and lacks the distal phalanges, including 269 the ungual (Fig. 2a; Brusatte et al. 2013). The only known phalanx in the third manual digit of 270 Balaur has a tapering distal end with a small distal articular surface, suggesting the presence of a 271 possible additional phalanx of very small size. Such a reduction is unknown in dromaeosaurids, 272 which have three non-ungual phalanges on manual digit III and a fully functional ungual (Fig. 273 2d), but it is commonly found in non-confuciusornithid pygostylians, where the third manual 274 digit is usually reduced to two or fewer phalanges, the most distal of which has a tapering distal 275 end and poorly defined articular surfaces (e.g., Sinornis, Sapeornis, Zhouornis, Piscivoravis; 276 Sereno et al. 2002; Gao et al. 2012; Zhang et al. 2013; Zhou et al. 2014; see Fig. 2b-c, Fig. S1).

Dorsal margin of manual unguals does not arch dorsally above level of articular facet and flexor tubercles not expanded ventrally

279 Senter (2007a) argued that in dromaeosaurid manual unguals, the dorsal margins arch higher 280 than the articular facets when the latter is held vertically, and that this feature differentiates 281 dromaeosaurid manual unguals from those of other theropods. The derived condition is present 282 in microraptorines and eudromaeosaurs but is absent in unenlagiines (Senter 2007a; Senter 283 2007b; Currie and Paulina Carabajal 2012; Fig. S1A-B). Furthermore, the manual unguals in 284 both dromaeosaurids and troodontids bear prominent and dorsoventrally expanded flexor 
285 tubercles. Following the method described by Senter (2007a), we note that the dorsal margins of 286 Balaur's manual unguals do not arch higher than the articular facet, and that the flexor tubercles 287 are relatively low and more elongate proximodistally than they are deep dorsoventrally (Brusatte 288 et al. 2013 figs. 21-22, figs. 21-22; Fig. S1C). Similar absence of a markedly convex dorsal 289 margin of the manual ungual and relatively moderate development of the flexor tubercles is 290 widespread among the manual unguals of basal avialans (e.g., Sinornis, Sapeornis, Zhouornis,

291 Piscivoravis; Sereno et al. 2002; Gao et al. 2012; Zhang et al. 2013; Zhou et al. 2014; see Fig. 292 2b-c).

\section{Complete coossification of pelvic bones}

294 Balaur displays coossification of the pelvic bones such that both the iliopubic and ilioischial 295 sutures are obliterated (Brusatte et al. 2013, Fig. S2A). In most tetanuran theropods, including 296 basalmost avialans, the pelvic elements do not completely coossify (e.g., Allosaurus, Jeholornis, 297 Patagonykus, Sapeornis, Tyrannosaurus; Madsen 1976; Novas 1997; Zhou and Zhang 2002;

298 Brochu 2003; Zhou and Zhang 2003). This contrasts with ceratosaurian-grade theropods

299 (Tykoski and Rowe 2004), some non-avialan coelurosaurs (e.g., Avimimus; Kurzanov 1981) and 300 ornithothoracines (e.g., Apsaravis, cf. Enantiornis, Patagopteryx, Qiliania, Sinornis; Chiappe 301 2002; Chiappe and Walker 2002; Clarke and Norell 2002; Sereno et al. 2002; Ji et al. 2011, Fig. 302 S2D) in which the pelvic bones fuse completely. Although coossification of the ilium to the 303 pubis is present in the only known specimen of the microraptorine dromaeosaurid

304 Hesperonychus, the pelvic coossification differs from Balaur and avialans as the ilioischial 305 articulation remains unfused (Longrich and Currie 2009).

306 Ridge bounding the cuppedicus fossa confluent with the acetabular rim

307 In the ilium of Balaur, the ridge that dorsally bounds the cuppedicus fossa is extended 308 posteriorly on the lateral surface of the pubic peduncle and is confluent with the acetabular rim 309 (Brusatte et al. 2013; Fig. S2A). This feature is a compound character formed by the presence of 310 a ridge bounding the cuppedicus fossa, which is a neotetanuran synapomorphy (Hutchinson 311 2001; Novas 2004), and the posterior extension of the cuppedicus fossa on the lateral surface of 312 the pubic peduncle, which is a derived feature of paravians (Hutchinson 2001, figs. 4-6). The 313 combination of features present in Balaur is shared by Anchiornis and Xiaotingia (Turner et al. 314 2012), Unenlagia and Rahonavis (Novas 2004), Velociraptor (Norell and Makovicky 1999) and 
315 enantiornithines (e.g., Sereno et al. 2002, fig. 8.4; Walker and Dyke 2009, Fig. S2D). The

316 presence and extent of the cuppedicus fossa is difficult to determine in most Mesozoic avialans

317 because of the two-dimensional preservation of most specimens (Novas 2004). Furthermore, the

318 character statements relative to the ridge bounding the cuppedicus fossa in phylogenetic analyses

319 are marked as 'inapplicable' in those taxa lacking a distinct cuppedicus fossa (Hutchinson 2001;

320 e.g., Mahakala, Patagopteryx, Ornithurae; Turner et al. 2011), a scoring strategy followed by

321 both Turner et al. (2012) and Godefroit et al. (2013a).

322 Pubis and ischium projected strongly posteroventrally and subparallel

323 Balaur has a posteroventrally directed pubis, subparallel to the ischium (Csiki et al. 2010; Fig.

324 S2A). Although Brusatte et al. (2013) acknowledged that the extreme posterior inclination of the

325 pubis may partially be the result of taphonomic distortion, they confirmed the genuine

326 posteroventral orientation of this bone. Within Theropoda, retroversion of the pubis

327 (opisthopuby) is known in therizinosauroids, parvicursorine alvarezsaurids, dromaeosaurids and

328 pygostylians. Most therizinosauroids (but not Falcarius) show a posteroventrally directed pubis

329 that articulates with the obturator process of the ischium (Zanno 2010). Opisthopuby is present in

330 many parvicursorines (e.g., Mononykus; Perle et al. 1994), but absent in more basal

331 alvarezsauroids (e.g., Haplocheirus, Patagonykus; Novas 1997; Choiniere et al. 2010). A

332 retroverted pubis is absent in basal paravians - they instead display a vertically oriented

333 ('mesopubic') pubis - and is present in some dromaeosaurids (e.g., Adasaurus and Velociraptor;

334 Norell and Makovicky 1999; Xu et al. 2010; Turner et al. 2012) but absent in others (e.g.,

335 Achillobator, Utahraptor; Perle et al. 1999; Senter et al. 2012). It is also a common feature in

336 pygostylian birds (e.g., Confuciusornis, Patagopteryx, Sapeornis; Chiappe et al. 1999;

337 Hutchinson 2001; Chiappe 2002; Chiappe and Walker 2002; Zhou and Zhang 2003).

338 Broad pelvic canal with laterally convex pubes and abrupt distal narrowing of interpubic 339 distance

340 Brusatte et al. (2013) noted as an autapomorphy of Balaur an interpubic distance that is

341 proportionally greater than that present in other dromaeosaurids (e.g., Velociraptor; Norell and

342 Makovicky 1997; Norell and Makovicky 1999). The gap between the laterally bowed pubes of

343 Balaur only begins to narrow abruptly in the distalmost third of the bone (Fig. 3b, Fig. S2B;

344 Brusatte et al. 2013, fig. 56). This condition differs from that seen in most theropods (e.g., 
345 Avimimus, Sinraptor, Tyrannosaurus; Currie and Zhao 1993; Vickers-Rich et al. 2002; Brochu

346 2003), including Velociraptor (Fig. 3d, Fig. S2C; Norell and Makovicky 1999; Brusatte et al.

347 2013), Bambiraptor (Burnham 2004) and Archaeopteryx (Norell and Makovicky 1999, fig. 25),

348 where the narrowing is more gradual over the length of the pubes and the pubis is not bowed

349 laterally in anteroposterior view. Brusatte et al. (2013) noted that the condition in Balaur is

350 somewhat similar to the condition in therizinosaurids (Zanno 2010). The combination of a

351 relatively broad pelvic canal, bounded by laterally convex pubes and with an abrupt distal

352 narrowing of the interpubic distance, is also seen in pygostylian birds (e.g., Concornis,

353 Dapingfangornis, Piscivoravis, Sapeornis, Yanornis; Sanz et al. 1995; Zhou and Zhang 2003; Li

354 et al. 2006; Zhou et al. 2014; Zheng et al. 2014; see Figs. 3c, Fig. S2E).

355 Ischial tuberosity

356 The ischium of Balaur bears a well-developed obturator tuberosity (ischial tuberosity of

357 Hutchinson 2001) on the dorsal end of the part of its anterior margin that contacts or nearly

358 contacts the pubis ventrally (Brusatte et al. 2013). This feature was determined to be a

359 synapomorphy of the velociraptorine subclade (including Balaur) by Turner et al. (2012).

360 However, almost all non-velociraptorine taxa were scored by them as either unknown for or

361 lacking an ischial tuberosity (char. 176 in Turner et al. 2012), with only Adasaurus, Anchiornis,

362 Deinonychus and Velociraptor scored as bearing that feature. Nevertheless, a prominent ischial

363 tuberosity is also present in avialans, in particular in large-bodied flightless taxa (e.g.,

364 Patagopteryx; Hutchinson 2001). The ischial tuberosity of some avialans approaches and

365 contacts the pubis (e.g., Dromaius; ACUB 3131), and is the case in Balaur.

366 Ischium with proximodorsal flange

367 The ischium of Balaur bears a process along the dorsal half of its dorsal surface (Brusatte et al.

368 2013, fig. 27A: "dorsal flange of proximal ischium"). This process is topographically equivalent

369 to the proximal dorsal ischial tuberosity of other reptiles (Hutchinson 2001). This structure is

370 variably developed on the ischia of many paravians (e.g., Novas and Puerta 1997; Forster 1998;

371 Xu et al. 1999; Agnolín and Novas 2013). In unenlagiines and microraptorines, the ischium bears

372 a tuber-like proximodorsal process (Novas and Puerta 1997; Agnolín and Novas 2013, figs. 3.5c-

373 e) which is absent in known velociraptorines (Norell and Makovicky 1999; Agnolín and Novas

374 2013; Brusatte et al. 2013) except for a Velociraptor-like taxon from Mongolia (Norell and 
375 Makovicky 1999, fig 24). In basal avialans, the ischial tuberosity is developed as a prominent

376 trapezoidal flange which is more proximodistally expanded than it is in other paravians and

377 which resembles the condition present in Balaur (e.g., Confuciusornis, cf. Enantiornis,

378 Jeholornis, Patagopteryx, Sapeornis, Sinornis; Chiappe et al. 1999; Hutchinson 2001; Sereno et

379 al. 2002; Zhou and Zhang 2002; Zhou and Zhang 2003; Walker and Dyke 2009; see Agnolín and

380 Novas 2013; Fig. S2D, F).

381 Fibula fused to tibia proximally

382 In Balaur, the tibia and the fibula are fused proximally (Brusatte et al. 2013), a condition not

383 seen in dromaeosaurids or most non-avialan theropods. Among coelurosaurs, a more extensive

384 proximal fusion between tibia and fibula is present in pygostylian birds (e.g., Qiliania; Ji et al.

385 2011).

386 Tuber and ridge along lateral surface of the distal end of the tibiotarsus

387 The distal end of the tibiotarsus of Balaur bears a pronounced anteroposteriorly oriented lateral

388 ridge. The ridge is most pronounced anteriorly, where it terminates at a discrete rounded tubercle

389 located at the point where the lateral condyle and shaft merge. The ridge is kinked at its midpoint

390 where it forms a second, ventrally directed tubercle positioned laterodistally relative to the first

391 tubercle (Brusatte et al. 2013, fig. 35). Brusatte et al. (2013) suggested that the first tubercle may

392 represent the distal end of the fibula, fused to the tibiotarsus, whereas no interpretation of the

393 second tubercle was provided. A raised ridge along the anterolateral margin of the distal end of

394 the tibiotarsus at the point of fusion between the tibia and the proximal tarsals is also present in

395 Qiliania (Ji et al. 2011) and in the enigmatic Haţeg taxon Bradycneme (Harrison and Walker

396 1975). Based on comparison with birds, we interpret the second tubercle and the corresponding

397 kinked ridge as the fibular facet of the calcaneum. According to our interpretation, the other

398 (more proximally placed) tubercle is topographically equivalent to the tuberculum retinaculi $M$.

399 fibularis of birds (Baumel and Witmer 1993).

400 Complete distal co-ossification of the tibiotarsus

401 The distal end of the tibia and the proximal tarsals of Balaur are coossified, forming a tibiotarsus

402 where the sutures are obliterated (Brusatte et al. 2013). Turner et al. (2012) considered the fusion

403 between the calcaneum and astragalus, but not the tibia and tarsals, to be a synapomorphy of

404 Paraves. Fusion involving the proximal tarsals and the distal end of the tibia is a condition seen 
405 in some basal neotheropods (Tykoski and Rowe 2004). Within non-avialan coelurosaurs, 406 coossification of the proximal tarsals and the distal end of the tibia is observed in alvarezsaurids 407 (e.g., Albinykus, Mononykus; Perle et al. 1994; Nesbitt et al. 2011) and some oviraptorosaurs 408 (e.g., Avimimus, Elmisaurus; Osmólska 1981; Vickers-Rich et al. 2002). Within Avialae, the 409 presence of a fully coossified tibiotarsus is present in taxa more crownward than Archaeopteryx 410 (e.g., Apsaravis, Confuciusornis, Hollanda; Chiappe et al. 1999; Clarke and Norell 2002; Bell et 411 al. 2010).

412 Deep extensor groove on distal tibiotarsus

413 Balaur bears a deep and prominent extensor groove on the distal end of the tibiotarsus (Brusatte 414 et al. 2013). Within dromaeosaurids, this feature has otherwise been reported only in 415 Buitreraptor and is homoplastically present in other maniraptoran lineages (e.g., Apsaravis, 416 Hollanda, Mononykus; Perle et al. 1994; Clarke and Norell 2002; Bell et al. 2010).

417 Tibiotarsus with intercondylar sulcus extended along the posterior surface

418 The distal end of Balaur's tibiotarsus is saddle-shaped due to the presence of a large and distinct 419 intercondylar sulcus (Brusatte et al. 2013). The latter feature is restricted not only to the 420 anterodistal end of the bone but also extends along the distal end of the posterior surface as a 421 flexor sulcus. This feature is also present in basal avialans known from three-dimensionally 422 preserved specimens (e.g., Apsaravis, Hollanda; Clarke and Norell 2002; Bell et al. 2010).

\section{Deep circular pit on medial surface of distal tibiotarsus}

424 The medial surface of the distal end of Balaur's tibiotarsus is excavated by a deep subcircular pit 425 which was described as being deeper than are the homologous depressions variably present in the 426 astragali of some dromaeosaurids (Brusatte et al. 2013). A pit comparable in depth to that present 427 in Balaur is also present in avialans more crownward than Archaeopteryx (depressio 428 epicondylaris medialis, Baumel and Witmer 1993) and has been considered a phylogenetically 429 informative feature (see O'Connor et al. 2011).

430 Extensive coossification of tarsometatarsus

431 The tarsometatarsal elements of Balaur display extensive coossification (Fig. 4a, Figs. S3-4;

432 Brusatte et al. 2013), in contrast to most non-avian theropods in which no such fusion is present 433 (e.g., Velociraptor; see Fig. 4b, Fig. S4A). Many maniraptoran lineages display coossification of 
434 the distal tarsals to the proximal ends of the metatarsals (e.g., Avimimus, Adasaurus, Albinykus, 435 Elmisaurus; Kurzanov 1981; Osmólska 1981; Nesbitt et al. 2011; Turner et al. 2012). However, 436 the extensive coossification of the metatarsal shafts is a character present only in Balaur and 437 pygostylians (e.g., Bauxitornis, Confuciusornis, Evgenavis, Hollanda, Patagopteryx, Vorona, 438 Yungavolucris; Chiappe 1993; Chiappe et al. 1999; Chiappe 2002; Forster et al. 2002; Bell et al. 439 2010; Dyke and Ösi 2010; O'Connor et al. 2014; see Fig. 4c, Fig. S3, Fig. S4C-D).

440 Metatarsals with one or more longitudinal eminences on the dorsal surface of the shafts

441 The shafts of Balaur's second to fourth metatarsals are dorsoventrally deep in cross-section,

442 being strongly convex along the extensor surfaces except for the area of contact between

443 metatarsals II and III. Here, the lateral edge of metatarsal II and the medial edge of metatarsal III 444 form dorsoventrally shallow, longitudinally arranged flanges that, together, form a depressed 445 region between the remainder of the metatarsal shafts. This unusual character combination, 446 which is not observed in non-avialan theropods, was considered to be an autapomorphy of 447 Balaur by Brusatte et al. (2013). However, comparable features are present in several Mesozoic 448 avialans. Vorona possesses two distinct ridges that extend along the distal halves of the extensor 449 surfaces of both metatarsals III and IV, delimiting a depressed intermetatarsal space (Forster et 450 al. 2002). A depressed area between metatarsals II and III is also present in Patagopteryx 451 (Chiappe 2002). The extensor surfaces of metatarsals II and III are markedly convex transversely 452 in many avisaurids with depressed areas present between the metatarsal shafts (e.g., Avisaurus, 453 Bauxitornis; Chiappe 1993; Dyke and Ösi 2010; Fig. S3H). Yungavolucris is reported to lack a 454 dorsally convex third metatarsal; however, the shaft's extensor surface at the proximal end of 455 metatarsal III bears a centrally positioned, longitudinally oriented eminence comparable to the 456 condition in Balaur (Chiappe 1993). Finally, the enigmatic avialan Mystiornis also bears distinct 457 longitudinal ridges along the extensor surfaces of metatarsals II-IV (Kurochkin et al. 2010).

Enlarged extensor fossa on distal end of metatarsal II

459 In most theropods, the distal end of metatarsal II bears an extensor fossa proximal to the articular 460 end. This fossa usually appears as a pit delimited by distinct margins and does not extend 461 mediolaterally across the entire extensor surface (e.g., Allosaurus, Deinonychus, Tyrannosaurus; 462 Ostrom 1969; Madsen 1976; Brochu 2003). In Balaur, the extensor fossa of metatarsal II is 463 enlarged and extends across the whole distal surface, bounded laterally by a raised ridge 
464 converging with the trochlea (Brusatte et al. 2013; Fig. S3B). A large, proximodistally enlarged 465 extensor fossa is present on the second metatarsal of Evgenavis (O'Connor et al. 2014; Fig. S3F). 466 An enlarged extensor fossa on metatarsal II, lacking distinct margins and bounded laterally by a 467 raised margin, is also present in Parabohaiornis (Wang et al. 2014a) and Yungavolucris 468 (Chiappe 1993; Fig. S3E).

469 Metatarsal II with plantarly projected medial condyle

470 Balaur bears a plantarly projected medial condyle on the distal end of metatarsal II, visible in 471 medial view as a distinct ventral projection of the distal end (Brusatte et al. 2013; Fig. S3A). In 472 most theropods, including dromaeosaurids, the medial condyle of metatarsal II does not project 473 plantarly more than the lateral condyle (e.g., Deinonychus, Eustreptospondylus, Falcarius,

474 Garudimimus, Sinraptor, Talos, Tyrannosaurus, Zuolong; Ostrom 1969; Currie and Zhao 1993;

475 Brochu 2003; Kirkland et al. 2004; Kobayashi and Barsbold 2005; Sadleir et al. 2008; Choiniere 476 et al. 2010; Zanno et al. 2011). Many avialans bear a plantarly unexpanded medial condyle on 477 metatarsal II and hence resemble other theropods (e.g., Avisaurus, Mystiornis, Yungavolucris; 478 Chiappe 1993; Kurochkin et al. 2010). However, a plantarly projected medial condyle like that 479 present in Balaur is present in the basal pygostylians Confuciusornis and Evgenavis (O'Connor 480 et al. 2014; Fig. S3G, I) and in the ornithuromorph Apsaravis (Clarke and Norell 2002).

481

482

483

484

485

486

487

488

489

490

491

492

493

\section{Metatarsal II lacks prominent ginglymoid distal end}

The presence of a prominent extensor sulcus on the second metatarsal is regarded as a synapomorphy of Dromaeosauridae (Turner et al. 2012). Balaur possesses a broadly convex distal end of metatarsal II that lacks a ginglymoid distal articulation with a well-developed extensor sulcus (Fig. 4a; see Norell and Makovicky 1997; Brusatte et al. 2013; Fig. S3B). Some avialan taxa also bear a distinct extensor sulcus on metatarsal II like that present in dromaeosaurids (e.g., Avisaurus, Yungavolucris; Chiappe 1993; Fig. S3C, E) whereas others bear a broadly convex articular facet and hence resemble Balaur (e.g., Bauxitornis, Evgenavis; Dyke and Ösi 2010; O'Connor et al. 2014; Fig. S3D, F).

\section{Distal articular surface of metatarsal II narrower than maximum width of its distal end}

The width of the distal articular surface of metatarsal II in Balaur is less than the width of the entire distal end of the metatarsal (Brusatte et al. 2013; Fig. S3B). In extensor view, a large nonarticular region is present both lateral and medial to the articular surface. The metatarsals of most 
494 therizinosauroids show a similar condition (e.g., Segnosaurus; Perle 1979). The same feature 495 also occurs in the second metatarsal of some avisaurid avialans, where distinct non-articular 496 mediolateral expansions are present proximal to the distal articular surface (Avisaurus 497 archibaldi, A. gloriae; Chiappe 1993; Varricchio and Chiappe 1995; Fig. S3C).

498 Shaft of metatarsal IV anteroposteriorly compressed and mediolaterally widened

499 In most theropods, the mid-length cross section of metatarsal IV is subcircular, or

500 anteroposteriorly thicker than wide. In Balaur, the mid-length cross section of metatarsal IV is

501 anteroposteriorly compressed and mediolaterally expanded (Brusatte et al. 2013), a characteristic

502 that is also seen in both velociraptorine (e.g., Deinonychus, Velociraptor and Adasaurus) and

503 dromaeosaurine dromaeosaurids (e.g., Utahraptor), as well as basal troodontids (Turner et al.

504 2012). However, an anteroposteriorly compressed metatarsal IV with a flat cross section is also

505 present in basal avialans (e.g., Avisaurus, Mystiornis, Evgenavis, Yungavolucris; Brett-Surman

506 and Paul 1985; Chiappe 1993; Kurochkin et al. 2010; O'Connor et al. 2014; Fig. S3E, H).

507 Short and robust metatarsal V

508 Dromaeosaurids bear a slender and elongate metatarsal V that is at least $40 \%$ of metatarsal III's

509 length (Fig 5c; Norell and Makovicky 1999; Hwang et al. 2002; Brusatte et al. 2013). Balaur

510 possesses a shorter and stouter metatarsal $\mathrm{V}$ that is less than $30 \%$ of metatarsal III's length (Fig

511 5a, Fig. S3A, S4B; Brusatte et al. 2013): it is thus more similar to the condition present in basal

512 avialans (e.g., Evgenavis, Sapeornis, Vorona; Forster et al. 2002; Zhou and Zhang 2003;

513 O'Connor et al. 2014) and most non-avialan coelurosaurs (e.g., Khaan, Segnosaurus,

514 Tyrannosaurus; Perle 1979; Brochu 2003; Balanoff and Norell 2012).

515 Hallux unreduced compared to other toes and functional

516 Balaur possesses a hallux that cannot be considered reduced in size compared to the other pedal

517 digits (Brusatte et al. 2013, Fig. S4B). Most non-avialan theropods, including dromaeosaurids,

518 possess a relatively small first pedal ungual (e.g., Allosaurus, Microraptor, Velociraptor;

519 Madsen 1976; Norell and Makovicky 1997; Hwang et al. 2002; Fig. S4A). However, a large and

520 falciform first pedal ungual that is not reduced compared to the other pedal unguals, as seen in

521 Balaur, is also present in many basal avialans (e.g., Confuciusornis, Jixiangornis, Patagopteryx,

522 Sapeornis, Zhouornis; Chiappe et al. 1999; Chiappe 2002; Ji et al. 2002; Zhou and Zhang 2003;

523 Zhang et al. 2013; Fig. S4D). Furthermore, the first phalanx in Balaur's hallux is subequal in 
524 length compared to the proximal phalanges of pedal digits II-IV, a condition present in basal 525 avialans (e.g., Jixiangornis, Sapeornis, Zhouornis; Ji et al. 2002; Zhou and Zhang 2003; Zhang et 526 al. 2013; Fig. S4) but not in non-avialan theropods. The distal placement of the articular end of 527 metatarsal I in Balaur relative to the trochlea of metatarsal II is more similar to that of basal 528 avialans (e.g., Confuciusornis, Patagopteryx; Chiappe et al. 1999; Chiappe 2002) than the more 529 proximally placed trochlea of metatarsal I in dromaeosaurids (e.g., Microraptor, Deinonychus, 530 Velociraptor; Norell and Makovicky 1997; Hwang et al. 2002; Fowler et al. 2011) and other 531 non-avialan theropods (e.g., Khaan, Balanoff and Norell 2012). In addition, the well-developed 532 articular surfaces indicate that the hallux of Balaur was dextrous, mobile and fully functional 533 (Brusatte et al. 2013). This is also the condition present in birds but contrasts with that of most 534 non-avialan theropods, including dromaeosaurids (Norell and Makovicky 1997).

535 Enlarged pedal ungual II lacking both marked falciform shape and prominent flexor tubercle

536 Balaur bears a hypertrophied second pedal ungual that is larger than the third and fourth pedal 537 unguals, similar to that seen in most deinonychosaurs (Turner et al. 2012; Brusatte et al. 2013).

538 However, Brusatte et al. (2013) noted that the second pedal ungual of Balaur does not show the 539 marked falciform shape and prominent flexor tubercle seen in most dromaeosaurids (e.g.,

540 Ostrom 1969; Turner et al. 2012). A robust second pedal digit with an enlarged and moderately

541 recurved ungual, comparable to the condition in Balaur, is also present among several avialans

542 (e.g., Bohaiornis, Fortunguavis, Jixiangornis, Parabohaiornis, Patagopteryx, Qiliania, Sulcavis,

543 Zhouornis; Chiappe 2002; Ji et al. 2002; Hu et al. 2011; Ji et al. 2011; O’Connor et al. 2013;

544 Zhang et al. 2013; Wang et al. 2014b; Wang et al. 2014A; Fig. S4D).

545 Penultimate phalanges of pedal digit III more than 1.2 times longer than preceding phalanx

546 In most theropods, including dromaeosaurids, the penultimate phalanx of the third pedal digit is

547 subequal to or shorter than the length of the preceding phalanges (e.g., Gallimimus, Khaan,

548 Tyrannosaurus, Velociraptor; Osmólska et al. 1972; Norell and Makovicky 1997; Brochu 2003;

549 Balanoff and Norell 2012; Brusatte et al. 2013, table 7). However, Balaur bears a relatively

550 elongate penultimate phalanx on pedal digit III that is 1.2 times longer than the preceding

551 phalanx (Brusatte et al. 2013; Fig. S4B). This condition is similar to that present in many

552 avialans (e.g., Concornis, Sapeornis, Zhouornis; Sanz et al. 1995; Zhou and Zhang 2003; Zhang

553 et al. 2013; Fig. S4D) and unlike that of dromaeosaurids and most non-avialan theropods. 
554 Pedal ungual IV reduced in size

555 Balaur's fourth pedal ungual, although distally incomplete in the holotype specimen, is the 556 smallest of the pedal unguals (about $60 \%$ the size of pedal ungual III, see Brusatte et al. 2013;

557 Fig. S4B). This condition differs from that seen in dromaeosaurids, Sapeornis and some

558 troodontids in which the fourth pedal unguals are more than $85 \%$ the length of the third pedal

559 ungual (e.g., Borogovia 140\%, Sapeornis 100\%; Osmólska 1987; Brusatte et al. 2013, table 7; Pu

560 et al. 2013). It does, however, resemble the condition in ornithothoracine birds (e.g., Bohaiornis

$56159 \%$, Parabohaiornis 60\%, Qiliania 76\%, Zhouornis 66\%; Hu et al. 2011; Ji et al. 2011; Zhang

562 et al. 2013; Fig. S4C-D). The relative length of the fourth pedal ungual in most maniraptorans is

563 intermediate between Balaur and dromaeosaurids, being 70-85\% the length of pedal ungual III

564 (e.g., Archaeopteryx 77-78\%, Khaan, Jixiangornis, Sinornithoides and Zhongjianornis 80\%;

565 Elzanowski 2001; Currie and Dong 2001; Ji et al. 2002; Zhou and Li 2010; Balanoff and Norell

566 2012, fig. 33).

\section{Results}

568

569

570

571

572

573

574

575

576

577

578

579

580

581

582

583

Modified Brusatte et al. (2014) analysis

The modified Brusatte et al. (2014) analysis produced $>999,999$ shortest cladograms of 3397 steps each $(\mathrm{CI}=0.3206, \mathrm{RI}=0.7771)$. In all the shortest trees found, Balaur was recovered as an avialan, as the sister-taxon of Sapeornis, and not as a member of Dromaeosauridae. The 'Balaur + Sapeornis' clade resolved as the sister-taxon of a clade including Pygostylia, Jixiangornis and Jeholornis. Exploration of the alternative topologies that we recovered resulted in Epidendrosaurus, Hesperonychus, Kinnareemimus, Pedopenna, Pyroraptor, and Shanag acting as 'wildcard' taxa among Maniraptora, and these taxa were pruned a posteriori from the results of the analyses to improve resolution within paravian taxa. After pruning the 'wildcard' taxa from the strict consensus topology (Fig. 5), Archaeopteryx was resolved as the sister-group to the rest of Avialae. Unambiguous synapomorphies for the sister taxon relationships between Balaur and Sapeornis are: anterior surface of deltopectoral crest with distinct muscle scar near lateral edge along distal end of crest for insertion of biceps muscle (139.1, homoplastic among maniraptorans); third manual digit with two or less phalanges (147.2, convergently developed among ornithothoracines); humeral condyles placed on anterior surface (366.1, convergently developed among therizinosauroids, alvarezsauroids and most avialans); anteroposterior 
584 diameter of metacarpal III less than $50 \%$ of the same diameter in metacarpal II (386.1); and

585 length of first phalanx of pedal digit I greater than $66 \%$ of first pedal phalanx of pedal digit III

586 (859.1, convergently developed among more crownward avialans).

587 Furthermore, all three versions of the dataset that used implied weighting recovered Balaur as an

588 avialan more crownward than Archaeopteryx (see Figure S5).

589 Modified Lee et al. (2014) analysis

590 The modified Lee et al. (2014) analysis recovered 1152 shortest trees of 6350 steps each $(\mathrm{CI}=$

$5910.2672, \mathrm{RI}=0.5993)$. The strict consensus of the shortest trees found is in general agreement

592 with the Maximum Clade Credibility Tree recovered by Lee et al. (2014), the most relevant

593 difference being the unresolved polytomy among Aurornis, Jinfengopteryx, Dromaeosauridae,

594 Troodontidae and Avialae (Fig. 6). The a posteriori pruning of the above mentioned genera does

595 not resolve the polytomy among the three suprageneric clades. It is noteworthy that an

596 unresolved polytomy among the main paravian lineages was also obtained by Brusatte et al.

597 (2014), and by our updated version of the latter dataset. In all trees found, Balaur was resolved

598 as a basal avialan and as the sister taxon of Pygostylia (the 'Zhongjianornis + (Sapeornis + more

599 crownward avialans)' clade), in agreement with the results of previous versions of this matrix

600 (i.e., Godefroit et al. 2013b). The character states unambiguously supporting this placement for

601 Balaur are: (1) presence of fusion between metacarpal II and the distal carpals (char. 311.1);

602 presence of a mediolaterally slender third metacarpal (char. 322.1); absence of the mediodorsal

603 process on the ischium (char. 423.0); presence of an elongate first phalanx of pedal digit I (char.

604 499.0); and presence of a completely fused tibiotarsus (char. 580.1). Nodal support for this

605 placement was low (Decay Index $=1$ ). However, higher nodal support values for nodes along the

606 less crownward part of Avialae support the placement of Balaur in this clade. This interpretation

607 is further supported by the implied weighting analyses of the data set: these analyses consistently

608 recovered Balaur as a non-pygostylian member of Avialae, located less crownward within

609 Avialae than was the case in the unweighted analysis, and bracketed by Archaeopteryx and all

610 other avialans (see Figure S6).

611 Templeton tests

612 We re-analysed the original dataset of Brusatte et al.'s (2014) enforcing the following backbone

613 constraint: ((Balaur, Anas), Troodon, Dromaeosaurus) (i.e., enforcing the analysis to retain only 
614 those topologies where Balaur is closer to modern birds than to either troodontids and

615 dromaeosaurids, thus by definition forcing it to be a member of Avialae; see Electronic

616 Supplementary Material). The shortest enforced topologies that resulted were 3368 steps long,

617 eight steps less parsimonious than the shortest unconstrained topologies that recovered Balaur

618 among Dromaeosauridae. This difference was not statistically significant based on the

619 Templeton test $(p>0.2059, \mathrm{~N}>37)$.

620 We also re-analysed the modified dataset of Brusatte et al. (2014), this time enforcing Balaur to

621 be a dromaeosaurid using the following backbone constraint: ((Balaur, Dromaeosaurus),

622 Troodon, Anas). The shortest enforced topologies that resulted were 3400 steps long, three steps

623 less parsimonious than the shortest unconstrained topologies where Balaur was recovered within

624 Avialae. This difference was not statistically significant based on the Templeton test $(p>0.7098$, $625 \mathrm{~N}>61)$.

626 Using the dataset modified from Lee et al. (2014), we enforced a dromaeosaurid 627 placement for Balaur, using the following backbone constraint: ((Balaur, Dromaeosaurus),

628 Troodon, Meleagris). The shortest trees found using that constraint are nine steps longer than the 629 shortest unforced topologies, and placed Balaur as the basalmost dromaeosaurid, excluded from 630 the ((Eudromaeosauria + Microraptoria) + Unenlagiinae) clade. This difference was not 631 statistically significant based on the Templeton test $(p>0.4400, \mathrm{~N}>125)$.

632 Finally, we also tested a velociraptorine placement for Balaur, using the following 633 backbone constraint: ((Balaur, Velociraptor), Dromaeosaurus, Troodon). The shortest trees 634 found using that constraint are 14 steps longer than the shortest unforced topologies, and placed 635 Balaur as the basalmost velociraptorine. This difference was not statistically significant based on 636 the Templeton test $(p>0.1580, \mathrm{~N}>89)$.

\section{Discussion}

639 Balaur possesses a unique and bizarre mix of characters, many of which were previously 640 considered exclusive to Deinonychosauria or Avialae, and which may challenge its placement in 641 either of the aforementioned clades. Godefroit et al. (2013b) tested alternative placements of 642 Balaur among Paraves, and recovered the dromaeosaurid placement for that taxon as a 643 suboptimal solution. Here, we have shown that an avialan placement for Balaur using the 644 original dataset of Brusatte et al. (2014) is a suboptimal solution that cannot be rejected using 
645 that dataset. Although the most parsimonious results of the two updated phylogenetic analyses 646 presented here concur in resolving Balaur within Avialae, the deinonychosaurian placement for 647 this taxon discussed by Brusatte et al. (2013) can be only tentatively rejected based on current 648 information. The most parsimonious placement was recovered under both equally weighted and 649 implied weighting analyses, suggesting that the avialan placement of Balaur was not biased by $a$ 650 priori assumptions on homoplasious character downweighting. Nevertheless, whatever the 651 placement for Balaur, a significant amount of homoplasy, due to both convergences and 652 reversals, is required to explain its unique morphology.

653 The sister taxon relationship recovered between Balaur and the short-tailed Sapeornis - resulting 654 from analysis of the dataset modified from Brusatte et al. (2014) - is quite unexpected, and may 655 be partially biased by the placement of the long-tailed Jeholornis and Jixiangornis as closer to 656 other short-tailed birds than Sapeornis (a relationship also recovered by the original dataset, 657 Brusatte et al. 2014). According to that topology, the short pygostyle-bearing tail of Sapeornis 658 evolved independently of the same condition in more crownward birds. The topology that results 659 from our use of the dataset modified from Lee et al. (2014) agrees with most analyses of avialan 660 relationships (e.g., Cau and Arduini 2008; O'Connor et al. 2011, 2013; Wang et al. 2014b) in 661 depicting a single origin of the pygostylian tail among birds.

662 Here we should note that topological discrepancies and alternative placements of 663 problematic taxa may be influenced by artefacts in coding practice, or by the logical basis of 664 character statement definition followed by different authors (Brazeau 2011). The datasets of 665 Brusatte et al. (2014) and Lee et al. (2014) differ from each other in the logical basis of their 666 respective character statements and definitions. The definitions of many characters used in the 667 analysis of Brusatte et al. (2014) impose congruence by linking more than one variable character 668 to a particular state (see Brazeau 2011 and references therein), or by mixing together neomorphic 669 and transformational characters as alternative states of the same character statements (see Sereno 670 2007). For example, the ordered character 178 of Brusatte et al. (2014) includes three 671 transformational states describing alternative extensions of the pubic apron along the pubis, 672 together with a fourth state describing a distinct phenomenon, the absence of the pubic apron (a 673 neomorphic character). Set that way, the absence of the pubic apron is a priori forced as a highly 674 derived (and much weighted) terminal state of a character describing a feature (the proximodistal 675 extent of the apron) that cannot be determined in those taxa lacking the apron. Character 
676 statements and definitions in the analysis of Lee et al. (2014) followed the recommendations

677 outlined by Sereno (2007) and Brazeau (2011); consequently, each character statement describes

678 a single variable character, and neomorphic and transformational characters were included as

679 separate character statements. To avoid the creation of spurious transformational optimizations

680 under some topologies, the characters in the analysis of Lee et al. (2014) were therefore atomized

681 in such a way as to capture both the presence or absence of the feature in addition to the states of

682 the feature (Brazeau 2011). Taxa scored as lacking a particular neomorphic character were

683 scored as 'unknown' for the transformational characters describing different conditions of the

684 same neomorphic feature.

685 We therefore consider it likely that some discrepancies between the updated analyses of

686 Brusatte et al. (2014) and Lee et al. (2014) - including the alternative placements of Balaur and

687 Sapeornis among basal avialans - reflect artefacts of coding rather than actual conflict in the

688 data. Nevertheless, it is noteworthy that even using distinct datasets, alternative character

689 weighting hypotheses and different logical bases for character definitions, Balaur was

690 consistently recovered as a basal avialan. Furthermore, the phylogenetic analysis of Foth et al.

691 (2014), which used the dataset of Turner et al. (2012) as their basis and which included an

692 expanded set of characters, independently found Balaur to be a basal avialan more crownward

693 than Archaeopteryx, but in a less crownward position than that presented here. In conclusion, we

694 consider the consensus among the results of these alternative tests (i.e., Balaur as a non-

695 pygostylian basal avialan) as the phylogenetic framework for the discussion on its evolution and 696 palaeoecology.

697 Implications for the palaeoecology of Balaur

698 In the absence of both extrinsic data on diet and craniodental remains there is no direct evidence

699 pertaining to the ecology and trophic adaptations of Balaur. Although not explicitly stated,

700 Brusatte et al.'s (2013) inferences regarding the ecology and diet of Balaur rest entirely on their

701 favoured phylogenetic placement of the taxon within the predatory deinonychosaurian clade

702 Velociraptorinae (see Carpenter 1998).

703 However, some aspects of Balaur's morphology do not support the hypothesis that its

704 ecomorphology was similar to that of dromaeosaurids. While there exists evidence that

705 dromaeosaurids employed both their hands and feet in predation (see Carpenter 1998), the

706 reduction in length and functionality of the third manual digit and the poor development or 
707 absence of the pedal characters linked with predatory behaviour in deinonychosaurs (i.e., 708 ginglymoid distal end of metatarsal II allowing extensive hyperextension, falciform second 709 ungual with prominent flexor tubercle; Ostrom 1969; Fowler et al. 2011), challenge the notion of 710 a specialised, dromaeosaurid-like predatory ecology for Balaur. Brusatte et al. (2013) interpreted 711 these unusual traits of Balaur as the result of insularism, although they acknowledged that 712 comparable morphological changes in insular taxa have so far not been reported in predatory 713 species. We are not aware of the reduction or loss of predatory adaptations in any insular 714 predatory taxon, and therefore consider it unlikely that the unique morphology of Balaur, in 715 particular the appendicular characters considered to be predatory adaptations among 716 dromaeosaurids, could be sufficiently accounted for by the 'island effect'.

717 Most of the features considered to be autapomorphies of Balaur by Csiki et al. (2010) and 718 Brusatte et al. (2013) are reinterpreted here as avialan synapomorphies. Consequently, these 719 traits were inherited by Balaur from its bird-like ancestors before its lineage was isolated in the 720 Haţeg environment. Since our analyses place Balaur among a grade of non-predatory avialans 721 including herbivorous and/or omnivorous species (Zhou and Zhang 2002; Dalsätt et al. 2006;

722 Zanno and Makovicky 2011), our preferred scenario does not necessitate a hypothesis of a 723 carnivorous ecology for this taxon and is thus more consistent with the absence of the 724 aforementioned predatory adaptations. Furthermore, in assuming a herbivorous or omnivorous 725 ecology for Balaur, the amount of morphological changes, particularly in limb shapes and 726 proportions, is comparable to that reported in several insular herbivorous and omnivorous taxa, 727 including both mammals (Sondaar 1977; Caloi and Palombo 1994; van der Geer et al. 2011) and 728 dinosaurs (e.g., Dalla Vecchia 2009). In particular, the presence in Balaur of a relatively broad 729 pelvic canal, the short and broad metatarsus with mediolaterally expanded distal ends relative to 730 the articular surfaces, and the presence of an enlarged first pedal digit is a combination of 731 features convergently acquired only by the non-predatory clade Therizinosauridae among 732 Mesozoic theropods (Zanno 2010; Zanno and Makovicky 2011).

733 However, we agree with previous authors that, regardless of its position within Paraves, 734 the morphology of Balaur includes a unique and unexpected combination of features, otherwise 735 seen in distinct maniraptoran lineages. Interestingly, Balaur independently evolved a series of 736 features previously reported in more crownward bird lineages, such as a deep depressio 737 epicondylaris medialis in the tibiotarsus, a hypertrophied extensor fossa in the second metatarsal, 
738 and dorsally convex metatarsals with expanded distal ends (characters elsewhere seen in some

739 ornithothoracines). A possible role of insularism in the origin of some of these traits is

740 acknowledged even in our preferred phylogenetic scenario. In particular, the results of our

741 analyses indicate that Balaur is phylogenetically bracketed by taxa showing relatively more

742 elongate forelimbs (humeral lengths usually more than $60 \%$ of the tibiotarsus + tarsometatarsus

743 length) and more robust forearms (ulna as thick as or thicker than the tibiotarsus). Accordingly,

744 we interpret the forelimb of Balaur as secondarily reduced. Flightlessness has also been inferred

745 in the ornithurine Gargantuavis from the Campanian-Maastrichtian of southern France

746 (Buffetaut and Loeuff 1998), indicating that distinct avialan lineages endemic to Late Cretaceous

747 Europe reduced or lost their flight adaptations. Several bird clades independently evolved

748 flightlessness during the Cenozoic as a result of their exploitation of insular environments and

749 the taxa concerned typically displayed apomorphic reduction of the forelimbs compared to those

750 of their closest relatives (Paul 2002; Naish 2012). Therefore, the reduced forelimb of Balaur may

751 be interpreted as the result of insularism.

752 Finally, existing skeletal and life reconstructions of Balaur have interpreted it as a

753 velociraptorine-like dromaeosaurid (Csiki et al. 2010; Brusatte et al. 2013). Does our re-

754 interpretation of this taxon as a member of Avialae require that previous hypotheses about its

755 appearance should be modified? By combining the known elements of Balaur with those of other

756 paravians, a new skeletal reconstruction has been produced (Fig. 7). As our knowledge of

757 Mesozoic paravian diversity has improved, it has become ever clearer that early members of the

758 deinonychosaurian and avialan lineages were highly similar in proportions, detailed anatomy and

759 life appearance: consequently, an 'avialan interpretation' of Balaur does not result in an animal

760 obviously different from a 'dromaeosaurid interpretation'. This conclusion has been supported

761 by recent quantitative analyses that demonstrate a significant degree of shared morphospace

762 between basal avialan taxa and their closest paravian relatives (e.g., Brusatte et al. 2014).

763 Nevertheless, we suggest that Balaur may have been proportionally shorter-tailed and with a less

764 raptorial-looking foot than previously depicted (Csiki et al. 2010; Brusatte et al. 2013). Clearly,

765 details of its cranial and dental anatomy are speculative. We assume that, like other paravians,

766 Balaur was extensively feathered.

\section{Conclusions}

768 The Maastrichtian paravian theropod Balaur bondoc is reinterpreted here as a basal avialan 
769 rather than as a dromaeosaurid. Features supporting its placement among Avialae include the

770 hypertrophied and proximally placed coracoid tubercle, the anterior placement of the condyles of

771 the humerus, the proximally fused carpometacarpus with a laterally shifted semilunate carpal, the

772 closed intermetacarpal space, the reduced condyles on metacarpals I-II, the slender metacarpal

773 III, the reduced phalangeal formula of the third digit, the extensively fused tibiotarsus, the

774 extensively fused tarsometatarsus, the distal placement of the articular end of first metatarsal, the

775 large size of the hallux, and the elongation of the penultimate phalanges of the pes. The absence

776 of dromaeosaurid synapomorphies (e.g., non-ginglymoid metatarsals II and III, short metatarsal

$777 \mathrm{~V}$ ) is thus interpreted as plesiomorphic, and not as the consequence of evolutionary reversal.

778 Both its phylogenetic bracketing within basal avialans and the absence of predatory adaptations

779 concur in indicating that Balaur was herbivorous or omnivorous, not predatory. The reduced

780 forelimb of Balaur represents one of the most compelling pieces of evidence for insular

781 adaptation in a Mesozoic bird. Furthermore, with its unique combination of features shared by

782 distinct paravian clades and its possible placement as one of the closest relatives of Pygostylia,

783 Balaur may represent a pivotal taxon in future investigations of Mesozoic bird interrelationships.

784 The hypothesis that some Mesozoic paravians represent the flightless descendants of

785 volant, Archaeopteryx-like ancestors, most vigorously promoted by Paul $(1988,2002)$, has not

786 been supported by recent phylogenetic hypotheses (e.g., Senter 2007b; Turner et al. 2012;

787 Agnolín and Novas 2013). Furthemore, phylogenetic analyses that incorporate sufficient

788 character data are able to differentiate the members of such paravian lineages as

789 Dromaeosauridae, Troodontidae and Avialae, as demonstrated by our present study.

790 Nevertheless, reinterpretation of Balaur as a flightless avialan reinforces the point that at least

791 some Mesozoic paravian taxa, highly similar in general form and appearance to dromaeosaurids,

792 may indeed be the enlarged, terrestrialised descendants of smaller, flighted ancestors, and that

793 the evolutionary transition involved may have required relatively little in the way of

794 morphological or trophic transformation.

\section{Acknowlegements}

796 We thank staff at the Transylvanian Museum Society (EME), Cluj-Napoca, in particular Matyas

797 and Marta Vremir for allowing access to the Balaur holotype, for discussion and substantial

798 invaluable assistance in Transylvania. DN and TB's work in Romania was funded by the

799 National Geographic Society. Critical comments by James Clark, Michael Pittman, and 
800 Academic Editor John Hutchinson greatly improved the quality of the manuscript. We thank

801 Steve Brusatte, Jonah Choiniere, Gareth Dyke and Corwin Sullivan for the detailed and critical

802 comments on an earlier version of this manuscript. The program TNT is being made available

803 with the sponsorship of the Willi Hennig Society. Jaime Headden kindly created and allowed use 804 of the image in Fig. 7.

805 


\section{Figure captions}

807 Figure 1. Comparison of the scapulocoracoid of (A) Balaur (lateral view) to that of (B) the 808 pygostylian Enantiophoenix (medial view); and (C) the dromaeosaurid Velociraptor (lateral 809 view); (A) after Csiki et al. (2010, fig. 1); (B) modified after Cau and Arduini (2003, fig. 2); (C)

810 after Norell and Makovicky (1999, fig. 4). All scapulocoracoids are drawn with the proximal half 811 of the scapular blade oriented horizontally to show relative placement of coracoid tubercle. Scale 812 bar: $10 \mathrm{~mm}$ (A); $5 \mathrm{~mm}$ (B); $10 \mathrm{~mm}$ (C). Abbreviations: ac, acromion; co, coracoid; ct, coracoid 813 tubercle; gl, glenoid; me, missing element; sc, scapula; snf, supracoracoid nerve foramen.

814 Figure 2. Comparison of the manus of (A) Balaur to those of (B) the enantiornithine Zhouornis;

815 (C) the pygostylian Sapeornis; and (D) the dromaeosaurid Deinonychus, showing bird-like

816 features of Balaur. (A) after Csiki et al. (2010, fig. 1, mirrored from original); (B) after Zhang et 817 al. (2013, fig. 7); (C) after Zhou and Zhang (2003, fig. 7); (D) after Wagner and Gauthier (1999, 818 fig. 2). All drawn at the same metacarpal II length. Scale bar: $20 \mathrm{~mm}$ (A, D); $10 \mathrm{~mm}$ (B, C). 819 Abbreviations: cis, closed intermetacarpal space; cmc, carpometacarpus; d3, reduced third digit; 820 drc, distally restricted condyles; lsc, laterally shifted semilunate carpal; p1-III, first phalanx of 821 manual digit 3; p2-III, second phalanx of manual digit 3; pec, proximally expanded extensor 822 surface; pnm, proximally narrow metacarpal I; U, ungual; usc, unfused semilunate carpal.

823 Figure 3. Pelvis of Balaur in lateral view (A). Comparison of the pubes of Balaur in

824 anteroventral view (B) to those of the pygostylian Sapeornis in anterior view (C), and the 825 dromaeosaurid Velociraptor in posterior view (D). (C) after Zhou and Zhang (2003, fig. 8); (D) 826 after Norell and Makovicky (1999, fig. 19). Scale bar: $10 \mathrm{~mm}$ (A, B, D), 2 mm (C).

827 Abbreviations: aa, antitrochanter; ac, acetabulum; cf, cuppedicus fossa; dfi, dorsal flange of 828 ischium; ipf, interpubic fenestra; is, ischium; pa, pubic apron; ps, pubic symphysis; pu, pubis, 829 sv, sacral vertebrae.

830 Figure 4. Comparison of the metatarsus and pes of (B) Balaur to that of (A) the dromaeosaurid 831 Velociraptor; and (C) the pygostylian Zhouornis. (A) after Norell and Makovicky (1997 figs. 6);

832 (C) after Zhang et al. (2013, fig. 8, mirrored from original). Scale bar: $20 \mathrm{~mm}$ (A, B); $10 \mathrm{~mm}$ (C). 833 Abbreviations: mt I, metatarsal I; mt V, metatarsal V; tt, tibiotarsus; U II: pedal ungual II; U IV, 834 pedal ungual IV.

835 Figure 5. Reduced strict consensus of the shortest trees from the analysis of the modified 836 Brusatte et al. (2014) matrix after pruning the 'wildcard' taxa Epidendrosaurus, Hesperonychus, 
837 Kinnareemimus, Pedopenna, Pyroraptor, and Shanag. Numbers adjacent to nodes indicate 838 Decay Index values $>1$.

839 Figure 6. Strict consensus tree of the shortest trees from the analysis of the modified Lee et al.

840 (2014) matrix. Numbers adjacent to nodes indicate Decay Index values.

841 Figure 7. Speculative skeletal reconstruction for Balaur bondoc, showing known elements in

842 white and unknown elements in grey. Note that the integument would presumably have

843 substantially altered the outline of the animal in life. Produced by Jaime Headden, used with

844 permission. 
846

847

848

849

850

851

852

853

854

855

856

857

858

859

860

861

862

863

864

865

866

867

868

869

870

871

872

873

874

875

876

\section{References}

Agnolín FL, Novas FE (2013) Avian Ancestors: A Review of the Phylogenetic Relationships of the Theropods Unenlagiidae, Microraptoria, Anchiornis and Scansoriopterygidae. Springer Agnolín FL, Novas FE (2011) Unenlagiid theropods: are they members of the Dromaeosauridae (Theropoda, Maniraptora)? Anais da Academia Brasileira de Ciências 83:117-162.

Allain R, Tykoski R, Aquesbi N, Jalil N-E, Monbaron M, Russell D, Taquet P (2007) An abelisauroid (Dinosauria: Theropoda) from the Early Jurassic of the High Atlas Mountains, Morocco, and the radiation of ceratosaurs. Journal of Vertebrate Paleontology 27:610-624.

Baier DB, Gatesy SM, Jenkins FA (2007) A critical ligamentous mechanism in the evolution of avian flight. Nature 445:307-310.

Balanoff AM, Norell MA (2012) Osteology of Khaan mckennai (Oviraptorosauria: Theropoda). Bulletin of the American Museum of Natural History 372:1-77.

Barsbold R, Currie PJ, Myhrvold NP, Osmólska H, Tsogtbaatar K, Watabe M (2000) A pygostyle from a non-avian theropod. Nature 403:155-156.

Baumel JJ, Witmer LM (1993) Osteologia. In: Baumel JJ, King AS, Breazile JE, Evans HE, Vanden Berge JC (eds) Handbook of avian anatomy: Nomina anatomica avium.

Publications of the Nuttall Ornithological Club, no. 25, pp 45-132

Bell AK, Chiappe LM, Erickson GM, Suzuki S, Watabe M, Barsbold R, Tsogtbaatar K (2010) Description and ecologic analysis of Hollanda luceria, a Late Cretaceous bird from the Gobi Desert (Mongolia). Cretaceous Research 31:16-26.

Brazeau MD (2011) Problematic character coding methods in morphology and their effects. Biological Journal of the Linnean Society 104:489-498.

Brett-Surman MK, Paul GS (1985) A new family of bird-like dinosaurs linking Laurasia and Gondwanaland. Journal of Vertebrate Paleontology 5:133-138.

Brochu CA (2003) Osteology of Tyrannosaurus rex: Insights from a nearly complete Skeleton and High-Resolution Computed Tomographic Analysis of the Skull. Journal of Vertebrate Paleontology 22:1-138.

Brusatte S, Lloyd G, Wang S, Norell M (2014) Gradual Assembly of Avian Body Plan Culminated in Rapid Rates of Evolution across the Dinosaur-Bird Transition. Current Biology 24:2386-2392.

Brusatte SL, Vremir M, Csiki-Sava Z, Turner AH, Watanabe A, Erickson GM, Norell MA 
877

878

879

880

881

882

883

884

885

886

887

888

889

890

891

892

893

894

895

896

897

898

899

900

901

902

903

904

905

906

907

(2013) The Osteology of Balaur bondoc, an Island-Dwelling Dromaeosaurid (Dinosauria: Theropoda) from the Late Cretaceous of Romania. Bulletin of the American Museum of Natural History 374:1-100.

Buffetaut E, Loeuff JL (1998) A new giant ground bird from the Upper Cretaceous of southern France. Journal of the Geological Society 155:1-4.

Burnham DA (2004) New information on Bambiraptor feinbergi from the Late Cretaceous of Montana. In: Currie PJ, Koppelhus EB, Shugar MA, Wright JL (eds) Feathered Dragons: Studies on the Transition from Dinosaurs to Birds. Indiana University Press, pp 67-111

Caloi L, Palombo MR (1994) Functional aspects and ecological implications in Pleistocene endemic herbivores of Mediterranean Islands. Historical Biology 8:151-172.

Cau A., Arduini P (2008) Enantiophoenix electrophyla gen. et sp. nov. (Aves, Enantiornithes) from the Upper Cretaceous (Cenomanian) of Lebanon and its phylogenetic relationships. Atti della Società Italiana di Scienze Naturali e del Museo Civico di Storia Naturale di Milano 149(II):293-324.

Cau A, Dyke GJ, Lee MSY, Naish D (2014) Data from: Sustained miniaturization and anatomical innovation in the dinosaurian ancestors of birds. Dryad Digital Repository doi: http://dx.doi.org/10.5061/dryad.jm6pj

Carpenter K (1998) Evidence of predatory behavior by carnivorous dinosaurs. Gaia 15:135-144.

Chiappe LM (2002) Osteology of the flightless Patagopteryx deferrariisi from the Late Cretaceous of Patagonia (Argentina). In: Chiappe LM, Witmer LM (eds) Mesozoic Birds: above the heads of dinosaurs. University of California Press, pp 281-361

Chiappe LM (1993) Enantiornithine (Aves) tarsometatarsi from the Cretaceous Lecho Formation of northwestern Argentina. American Museum Novitates 3083:1-27.

Chiappe LM, Shu-an J, Qiang J, Norell MA (1999) Anatomy and Systematics of the Confuciusornithidae (Theropoda Aves) from the Late Mesozoic of Northeast. Bulletin of the American Museum of Natural History 242:1-89.

Chiappe LM, Walker CA (2002) Skeletal morphology and systematics of the Cretaceous Euenantiornithes (Ornithothoraces: Enantiornithes). In: Chiappe LM, Witmer LM (eds) Mesozoic Birds: above the heads of dinosaurs. University of California Press, pp 240-267 Choiniere JN, Xu X, Clark JM, Forster CA, Guo Y, Han F (2010) A Basal Alvarezsauroid Theropod from the Early Late Jurassic of Xinjiang, China. Science 327:571-574. 
908 Clarke JA, Chiappe LM (2001) A new carinate bird from the Late Cretaceous of Patagonia 909 (Argentina). American Museum Novitates 1-24.

910 Clarke JA, Norell MA (2002) The morphology and phylogenetic position of Apsaravis ukhaana 911 from the Late Cretaceous of Mongolia. American Museum Novitates 1-46.

912 Csiki Z, Vremir M, Brusatte SL, Norell MA (2010) An aberrant island-dwelling theropod 913 dinosaur from the Late Cretaceous of Romania. Proceedings of the National Academy of $914 \quad$ Sciences 107:15357-15361.

915 Currie PJ, Paulina Carabajal A (2012) A new specimen of Austroraptor cabazai Novas, Pol, 916 Canale, Porfiri and Calvo, 2008 (Dinosauria, Theropoda, Unenlagiidae) from the latest 917 Cretaceous (Maastrichtian) of Río Negro, Argentina. Ameghiniana 49:662-667.

918 Currie PJ, Zhao X-J (1993) A new carnosaur (Dinosauria, Theropoda) from the Jurassic of 919 Xinjiang, People's Republic of China. Can J Earth Sci 30:2037-2081.

920 Currie PJ, Zhiming D (2001) New information on Cretaceous troodontids (Dinosauria, 921 Theropoda) from the People's Republic of China. Can J Earth Sci 38:1753-1766.

922 Dalla Vecchia FM (2009) Tethyshadros insularis, a new hadrosauroid dinosaur (Ornithischia) 923 from the Upper Cretaceous of Italy. Journal of Vertebrate Paleontology 29:1100-1116.

924 Dalsätt J, Zhou Z, Zhang F, Ericson PGP (2006) Food remains in Confuciusornis sanctus suggest 925 a fish diet. Naturwissenschaften 93:444-446.

Dyke GJ, Ösi A (2010) A review of Late Cretaceous fossil birds from Hungary. Geol J 45:434444.

Elzanowski A (2001) A new genus and species for the largest specimen of Archaeopteryx. Acta Palaeontologica Polonica 46:519-532.

930

Elzanowski A, Chiappe LM, Witmer LM (2002) Archaeopterygidae (Upper Jurassic of

931

932 Germany). In: Mesozoic Birds: Above the Heads of Dinosaurs. University of California

933 Forster CA (1998) The Theropod Ancestry of Birds: New Evidence from the Late Cretaceous of 934 Madagascar. Science 279:1915-1919.

935 Forster CA, Chiappe LM, Krause DW, Sampson SD (2002) Vorona berivotrensis, a primitive 936 bird from the Late Cretaceous of Madagascar. In: Chiappe LM, Witmer LM (eds) Mesozoic Birds: above the heads of dinosaurs. University of California Press, pp 268-280 938 Foth C, Tischlinger H, Rauhut OWM (2014) New specimen of Archaeopteryx provides insights 

into the evolution of pennaceous feathers. Nature 511:79-82.

940 Fowler DW, Freedman EA, Scannella JB, Kambic RE (2011) The Predatory Ecology of 941 Deinonychus and the Origin of Flapping in Birds. PLoS ONE 6:e28964.

942 Gao C, Chiappe LM, Zhang F, Pomeroy DL, Shen C, Chinsamy A, Walsh MO (2012) A subadult specimen of the Early Cretaceous bird Sapeornis chaoyangensis and a taxonomic reassessment of sapeornithids. Journal of Vertebrate Paleontology 32:1103-1112.

Godefroit P, Cau A, Dong-Yu H, Escuillié F, Wenhao W, Dyke G (2013a) A Jurassic avialan dinosaur from China resolves the early phylogenetic history of birds. Nature 498:359-362.

Godefroit P, Demuynck H, Dyke G, Hu D, Escuillié F, Claeys P (2013b) Reduced plumage and 948 flight ability of a new Jurassic paravian theropod from China. Nature Communications 4:1394.

Goloboff PA (1993) Estimating character weights during tree search. Cladistics 9:83-91. improves phylogenetic analysis of morphological data sets. Cladistics 24:758-773.

Goloboff PA, Farris JS, Nixon KC (2008b) TNT, a free program for phylogenetic analysis. Cladistics 24:774-786.

Harris J (2004) Confusing dinosaurs with mammals: Tetrapod phylogenetics and anatomical terminology in the world of homology. The Anatomical Record 281A:1240-1246. Cretaceous of Romania. Palaeontology 18:563-570.

Holtz TR, Jr. (1995) The arctometatarsalian pes, an unusual structure of the metatarsus of Cretaceous Theropoda (Dinosauria: Saurischia). Journal of Paleontology 14: 480-519.

961

962

963

964

965

966

967

968

Hu D, Li L, Hou L, Xu X (2011) A new enantiornithine bird from the Lower Cretaceous of western Liaoning, China. Journal of Vertebrate Paleontology 31:154-161.

Hu D, Xu X, Hou L, Sullivan C (2012) A new enantiornithine bird from the Lower Cretaceous of Western Liaoning, China, and its implications for early avian evolution. Journal of Vertebrate Paleontology 32:639-645.

Hutchinson JR (2001) The evolution of pelvic osteology and soft tissues on the line to extant birds (Neornithes). Zoological Journal of the Linnean Society 131:123-168.

Hwang SH, Norell MA, Qiang J, Keqin G (2002) New specimens of Microraptor zhaoianus (Theropoda: Dromaeosauridae) from northeastern China. American Museum Novitates 1- 
970

971

972

973

974

975

976

977

978

979

980

981

982

983

984

985

986

987

988

989

990

991

992

993

994

995

996

997

998

999

1000

44.

Ji Q, Ji S-A, Zhang H, You H, Zhang J, Wang L, Yuan C, Ji Z (2002) A new avialian bird Jixiangornis orientalis gen. et sp. nov. - from the Lower Cretaceous of Western Liaoning, NE China. Journal of Nanjing University (Natural Science) 38:723-736.

Ji S-A, Atterholt J, O’Connor JK, Lamanna MC, Harris JD, Li D-Q, You H-L, Dodson P (2011) A new, three-dimensionally preserved enantiornithine bird (Aves: Ornithothoraces) from Gansu Province, north-western China. Zoological Journal of the Linnean Society 162:201219.

Kirkland JI, Zanno LE, Sampson SD, Clark JM, DeBlieux DD (2004) A primitive therizinosauroid dinosaur from the Early Cretaceous of Utah. Nature 435:84-87.

Kobayashi Y, Barsbold R (2005) Reexamination of a primitive ornithomimosaur, Garudimimus brevipes Barsbold, 1981 (Dinosauria: Theropoda), from the Late Cretaceous of Mongolia. Can J Earth Sci 42:1501-1521.

Kurochkin EN, Dyke GJ, Karhu AA (2002) A new presbyornithid bird (Aves, Anseriformes) from the Late Cretaceous of southern Mongolia. American Museum Novitates 1-11.

Kurochkin EN, Zelenkov NV, Averianov AO, Leshchinskiy SV (2010) A new taxon of birds (Aves) from the Early Cretaceous of Western Siberia, Russia. Journal of Systematic Palaeontology 9:109-117.

Kurzanov SM (1981) On the unusual theropods from the Upper Cretaceous of Mongolia. Trudy Sovmestnay Sovetsko-Mongolskay Paleontologiyeskay Ekspeditsiy (Joint SovietMongolian Paleontological Expedition) 39-49.

Lee MSY, Cau A, Naish D, Dyke GJ (2014) Sustained miniaturization and anatomical innovation in the dinosaurian ancestors of birds. Science 345(6196): 562-566.

Li L, Ye D, Dongyu H, Li W, Shaoli C, Lianhai H (2006) New eoenantiornithid bird from the Early Cretaceous Jiufotang Formation of Western Liaoning, China. Acta Geologica Sinica - English Edition 80:38-41.

Lipkin C, Carpenter K (2008) Looking again at the forelimb of Tyrannosaurus rex. In: Larson PL, Carpenter K (eds) Tyrannosaurus rex, the Tyrant King. Indiana University Press, pp $166-190$

Longrich NR, Currie PJ (2009) Albertonykus borealis, a new alvarezsaur (Dinosauria: Theropoda) from the Early Maastrichtian of Alberta, Canada: implications for the 
systematics and ecology of the Alvarezsauridae. Cretaceous Research 30:239-252.

1002

1003

1004

1005

1006

1007

1008

1009

1010

1011

1012

1013

1014

1015

1016

1017

1018

1019

1020

1021

1022

1023

1024

1025

1026

1027

1028

1029

1030

1031

Madsen JH (1976) Allosaurus fragilis: a revised osteology. Utah Geological Survey Bulletin,

$$
\text { Salt Lake City }
$$

Makovicky PJ, Apesteguía S, Agnolín FL (2005) The earliest dromaeosaurid theropod from South America. Nature 437:1007-1011.

Naish D (2012) Birds. In: Brett-Surman MK, Holtz TR, Farlow JO (eds) The Complete Dinosaur (Second Edition). Indiana University Press, pp 379-423

Nesbitt SJ, Clarke JA, Turner AH, Norell MA (2011) A small alvarezsaurid from the eastern Gobi Desert offers insight into evolutionary patterns in the Alvarezsauroidea. Journal of Vertebrate Paleontology 31:144-153.

Norell M, Clark JM, Makovicky PJ (2001) Phylogenetic relationships among coelurosaurian dinosaurs. In: Ostrom JH, Gauthier J, Gall LF (eds) New perspectives on the origin and early evolution of birds: proceedings of the International Symposium in honor of John H. Ostrom. Peabody Museum of Natural History Yale University, pp 49-67

Norell MA, Makovicky PJ (1997) Important Features of the Dromaeosaurid Skeleton Information from a new specimen. American Museum Novitates 3215:1-28.

Norell MA, Makovicky PJ (1999) Important Features of the Dromaeosaurid Skeleton II: Information from Newly Collected Specimens of Velociraptor mongoliensis. American Museum Novitates 3282:1-45.

Novas FE (1997) Anatomy of Patagonykus puertai (Theropoda, Avialae, Alvarezsauridae), from the Late Cretaceous of Patagonia. Journal of Vertebrate Paleontology 17:137-166.

Novas FE (2004) Avian traits in the ilium of Unenlagia comahuensis (Maniraptora, Avialae). In: Currie PJ, Koppelhus EB, Shugar MA, Wright JL (eds) Feathered Dragons: Studies on the Transition from Dinosaurs to Birds. Indiana University Press, pp 137-166

Novas FE, Puerta PF (1997) New evidence concerning avian origins from the Late Cretaceous of Patagonia. Nature 387:390-392.

O’Connor J, Chiappe LM, Bell AK (2011) Pre-modern birds: avian divergences in the Mesozoic. In: Dyke DG, Kaiser G (eds) Living Dinosaurs: The Evolutionary History of Modern Birds. John Wiley \& Sons, pp 39-114

O’Connor J, Zhang Y, Chiappe LM, Meng Q, Quanguo L, Di L (2013) A new enantiornithine from the Yixian Formation with the first recognized avian enamel specialization. Journal of 
Vertebrate Paleontology 33:1-12.

1033 O'Connor JK, Averianov AO, Zelenkov NV (2014) A confuciusornithiform (Aves, Pygostylia)-

1034 like tarsometatarsus from the Early Cretaceous of Siberia and a discussion of the evolution

1035 of avian hind limb musculature. Journal of Vertebrate Paleontology 34:647-656.

1036 Osmólska H (1981) Coossified tarsometatarsi in theropod dinosaurs and their bearing on the 1037 problem of bird origins. Palaeontologia Polonica 42:79-95.

1038 Osmólska H (1987) Borogovia gracilicrus gen. et sp. n., a new troodontid dinosaur from the Late 1039 Cretaceous of Mongolia. Acta Palaeontologica Polonica 32:133-150.

1040 Osmólska H, Roniewicz E (1970) Deinocheiridae, a new family of theropod dinosaurs.

1041 Palaeontologia Polonica 21:5-19.

1042 Osmólska H, Roniewicz E, Barsbold R (1972) A new dinosaur, Gallimimus bullatus n. gen., n.

1043 sp. (Ornithomimidae) from the Upper Cretaceous of Mongolia. Palaeontologia Polonica

$1044 \quad 27: 104-143$.

1045 Ostrom JH (1976) Archaeopteryx and the origin of birds. Biological Journal of the Linnean 1046 Society 8:91-1982.

1047 Ostrom JH (1969) Osteology of Deinonychus antirrhopus, an Unusual Theropod from the Lower 1048 Cretaceous of Montana. Peabody Museul Bulletin 30:1-165.

1049 Paul GS (2002) Dinosaurs of the air: the evolution and loss of flight in dinosaurs and birds. Johns $1050 \quad$ Hopkins University Press, Baltimore

1051 Paul GS (1988) Predatory dinosaurs of the world: a complete illustrated guide. Simon \& 1052 Schuster, New York

1053 Perle A (1979) Segnosauridae - a new family of Theropoda from the Lower Cretaceous of

1054 Mongolia. Trudy, Sovmestnaâ Sovetsko - Mongol'skaâ paleontologičeskaâ èkspediciâ $1055 \quad 8: 45-55$.

1056 Perle A, Chiappe LM, Barsbold R, Clark JM, Norell MA (1994) Skeletal Morphology of 1057 Mononykus olecranus (Theropoda Avialae) from the Late Cretaceous of Mongolia. 1058 American Museum Novitates 3105:1-29.

1059 Perle A, Norell MA, Chiappe LM, Clark JM (1993) Flightless bird from the Cretaceous of 1060 Mongolia. Nature 362:623-626.

1061 Perle A, Norell MA, Clark JM (1999) A new maniraptoran theropod, Achillobator giganticus 1062 (Dromaeosauridae), from the Upper Cretaceous of Burkhant, Mongolia. Contributions 
1063 from the Geology and Mineralogy Chair, National University of Mongolia 1-105.

$1064 \mathrm{Pu} \mathrm{H}$, Chang H, Lü J, Wu Y, Xu L, Zhang J, Jia S (2013) A New Juvenile Specimen of

1065 Sapeornis (Pygostylia: Aves) from the Lower Cretaceous of Northeast China and

1066 Allometric Scaling of this Basal Bird. Paleontological Research 17:27-38.

1067 Sadleir R, Barrett PM, Powell HP (2008) The anatomy and systematics of Eustreptospondylus

1068 oxoniensis, a theropod dinosaur from the Middle Jurassic of Oxfordshire, England.

1069 Monograph of the Palaeontographical Society, London

1070 Sanz JL, Chiappe LM, Buscalioni AD (1995) The osteology of Concornis lacustris (Aves,

1071 Enantiornithes) from the Lower Cretaceous of Spain and a reexamination of its

1072 phylogenetic relationships. American Museum Novitates 3133:

1073 Senter P (2007a) A method for distinguishing dromaeosaurid manual unguals from pedal "sickle

1074 claws”. Bulletin of Gunma Museum of Natural History 11:1-6.

1075 Senter P (2007b) A new look at the phylogeny of coelurosauria (Dinosauria: Theropoda). Journal

1076 of Systematic Palaeontology 5:429-463.

1077 Senter P, Kirkland JI, DeBlieux DD, Madsen S, Toth N (2012) New Dromaeosaurids

1078 (Dinosauria: Theropoda) from the Lower Cretaceous of Utah, and the Evolution of the

1079 Dromaeosaurid Tail. PLoS ONE 7:e36790.

1080 Senter P, Robins JH (2005) Range of motion in the forelimb of the theropod dinosaur

1081 Acrocanthosaurus atokensis, and implications for predatory behaviour. Journal of Zoology

$1082 \quad 266: 307-318$.

1083 Sereno PC (2007) Logical basis for morphological characters in phylogenetics. Cladistics

$1084 \quad 23: 565-587$.

1085 Sereno PC, Chenggang R, Jianjun L (2002) Sinornis santensis (Aves: Enantiornithes) from the

1086 Early Cretaceous of northeastern China. In: Chiappe LM, Witmer LM (eds) Mesozoic

1087 Birds: above the heads of dinosaurs. University of California Press, pp 184-208

1088 Sondaar PY (1977) Insularity and its effect on mammal evolution. In: Hecht MK, Goody PC,

1089 Hecht BM (eds) Major Patterns in Vertebrate Evolution. Springer US, pp 671-707

1090 Templeton AR (1983) Phylogenetic inference from restriction endonuclease cleavage site maps

1091 with particular reference to the evolution of humans and the apes. Evolution 37:221.

1092 Turner AH, Makovicky PJ, Norell MA (2012) A Review of Dromaeosaurid Systematics and

1093 Paravian Phylogeny. Bulletin of the American Museum of Natural History 371:1-206. 
1094 Turner AH, Pol D, Clarke JA, Erickson GM, Norell MA (2007) A Basal Dromaeosaurid and 1095 Size Evolution Preceding Avian Flight. Science 317:1378-1381.

1096 Turner AH, Pol D, Norell MA (2011) Anatomy of Mahakala omnogovae (Theropoda:

1097 Dromaeosauridae), Tögrögiin Shiree, Mongolia. American Museum Novitates 1-66.

1098 Tykoski RS, Rowe TB (2004) Ceratosauria. In: Weishampel DB, Dodson P, Osmólska H (eds)

1099 The Dinosauria: Second Edition. University of California Press, pp 47-70

1100 van der Geer A, Lyras G, de Vos J, Dermitzakis M (2011) Evolution of island mammals:

1101 adaptation and extinction of placental mammals on islands. John Wiley \& Sons,

1102 Chichester, UK

1103 Varricchio DJ, Chiappe LM (1995) A new enantiornithine bird from the Upper Cretaceous Two

1104 Medicine Formation of Montana. Journal of Vertebrate Paleontology 15:201-204.

1105 Vickers-Rich P, Chiappe LM, Kurzanov SM (2002) The enigmatic birdlike dinosaur Avimimus

1106 portentosus. In: Chiappe LM, Witmer LM (eds) Mesozoic Birds: above the heads of

1107 dinosaurs. University of California Press, pp 65-86

1108 Wagner GP, Gauthier J (1999) 1,2,3 = 2,3,4: A solution to the problem of the homology of the

1109 digits in the avian hand. Proceedings of the National Academy of Science USA. 96:5111$1110 \quad 5116$.

1111 Walker C, Dyke G (2009) Euenantiornithine birds from the Late Cretaceous of El Brete

1112 (Argentina). Irish Journal of Earth Sciences 27:15-62.

1113 Wang M, O'Connor JK, Zhou Z (2014a) A new robust enantiornithine bird from the Lower

1114 Cretaceous of China with scansorial adaptations. Journal of Vertebrate Paleontology

$1115 \quad 34: 657-671$.

1116 Wang M, Zhou Z-H, O’Connor JK, Zelenkov NV (2014b) A new diverse enantiornithine family

1117 (Bohaiornithidae fam. nov.) from the Lower Cretaceous of China with information from

1118 two new species. Vertebrata Palasiatica 52:31-76.

1119 Welles SP (1984) Dilophosaurus wetherilli (Dinosauria, Theropoda). Osteology and

1120 comparisons. Palaeontographica Abteilung A A185:85-180.

1121 White MA, Falkingham PL, Cook AG, Hocknull SA, Elliott DA (2013) Morphological

1122 comparisons of metacarpal I for Australovenator wintonensis and Rapator

1123 ornitholestoides: implications for their taxonomic relationships. Alcheringa: An

$1124 \quad$ Australasian Journal of Palaeontology 37:435-441. 
1125 Xu X, Choiniere JN, Pittman M, Tan Q, Xiao D, Li Z, Tan L, Clark JM, Norell MA, Hone DWE, Sullivan C (2010) A new dromaeosaurid (Dinosauria: Theropoda) from the Upper Cretaceous Wulansuhai Formation of Inner Mongolia, China. Zootaxa 2403:1-9.

Xu X, Han F, Zhao Q (2014) Homologies and homeotic transformation of the theropod "semilunate" carpal. Scientific Reports 4:6042 doi: 10.1038/srep06042

Xu X, Wang X-L (2003) A new dromaeosaur (Dinosauria:Theropoda) from the Early Cretaceous Yixian Formation of Western Liaoning. Vertebrata Pal Asiatica 42:111-119.

Xu X, Wang X-L, Wu X-C (1999) A dromaeosaurid dinosaur with a filamentous integument from the Yixian Formation of China. Nature 401:262-266.

Zanno LE (2010) A taxonomic and phylogenetic re-evaluation of Therizinosauria (Dinosauria: Maniraptora). Journal of Systematic Palaeontology 8:503-543.

Zanno LE, Makovicky PJ (2011) Herbivorous ecomorphology and specialization patterns in theropod dinosaur evolution. PNAS 108:232-237.

Zanno LE, Varricchio DJ, O'Connor PM, Titus AL, Knell MJ (2011) A New Troodontid Theropod, Talos sampsoni gen. et sp. nov., from the Upper Cretaceous Western Interior Basin of North America. PLoS ONE 6:e24487.

Zhang Z, Chiappe LM, Han G, Chinsamy A (2013) A large bird from the Early Cretaceous of China: new information on the skull of enantiornithines. Journal of Vertebrate Paleontology 33:1176-1189.

Zhou Z-H, Zhang F (2002) A long-tailed, seed-eating bird from the Early Cretaceous of China. Nature 418:405-409.

Zhou Z, Clarke J, Zhang F (2008) Insight into diversity, body size and morphological evolution from the largest Early Cretaceous enantiornithine bird. Journal of Anatomy 212:565-577. 
1156 Zhou Z, Li FZZ (2010) A new Lower Cretaceous bird from China and tooth reduction in early

1157 avian evolution. Proceedings of the Royal Society of London B: Biological Sciences

$1158 \quad 277: 219-227$.

1159 Zhou Z, Zhang F (2003) Anatomy of the primitive bird Sapeornis chaoyangensis from the Early

1160 Cretaceous of Liaoning, China. Canadian Journal of Earth Sciences 40:731-747. 


\section{1}

Comparison between the scapulocoracoid of Balaur and other paravians.

Comparison of the scapulocoracoid of (A) Balaur (lateral view) to that of (B) the pygostylian Enantiophoenix (medial view); and (C) the dromaeosaurid Velociraptor (lateral view); (A) after Csiki et al. (2010, fig. 1); (B) modified after Cau and Arduini (2003, fig. 2); (C) after Norell and Makovicky $(1999$, fig. 4). All scapulocoracoids are drawn with the proximal half of the scapular blade oriented horizontally to show relative placement of coracoid tubercle. Scale bar: $10 \mathrm{~mm}$ (A); $5 \mathrm{~mm}$ (B); $10 \mathrm{~mm}$ (C). Abbreviations: ac, acromion; co, coracoid; ct, coracoid tubercle; gl, glenoid; me, missing element; sc, scapula; snf, supracoracoid nerve foramen. 
PeerJ Reviewing Manuscript

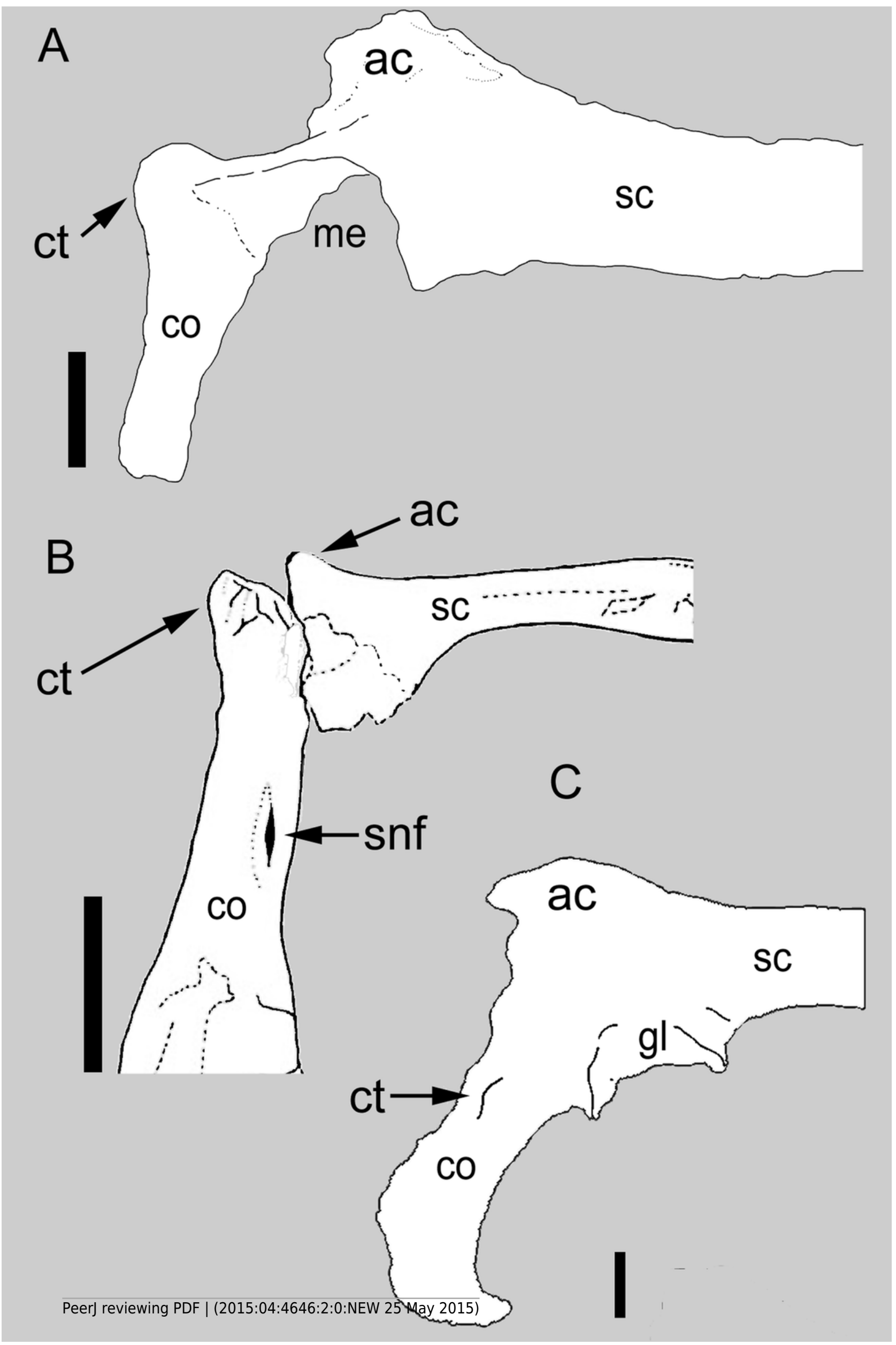


2

Comparison between the manus of Balaur and other paravians.

Comparison of the manus of (A) Balaur to those of (B) the enantiornithine Zhouornis; (C) the pygostylian Sapeornis; and (D) the dromaeosaurid Deinonychus, showing bird-like features of Balaur. (A) after Csiki et al. (2010, fig. 1, mirrored from original); (B) after Zhang et al. (2013, fig. 7); (C) after Zhou and Zhang (2003, fig. 7); (D) after Wagner and Gauthier (1999, fig. 2). All drawn at the same metacarpal II length. Scale bar: $20 \mathrm{~mm}(A, D) ; 10 \mathrm{~mm}(B, C)$. Abbreviations: cis, closed intermetacarpal space; cmc, carpometacarpus; d3, reduced third digit; drc, distally restricted condyles; Isc, laterally shifted semilunate carpal; p1-III, first phalanx of manual digit 3; p2-III, second phalanx of manual digit 3; pec, proximally expanded extensor surface; pnm, proximally narrow metacarpal I; U, ungual; usc, unfused semilunate carpal.

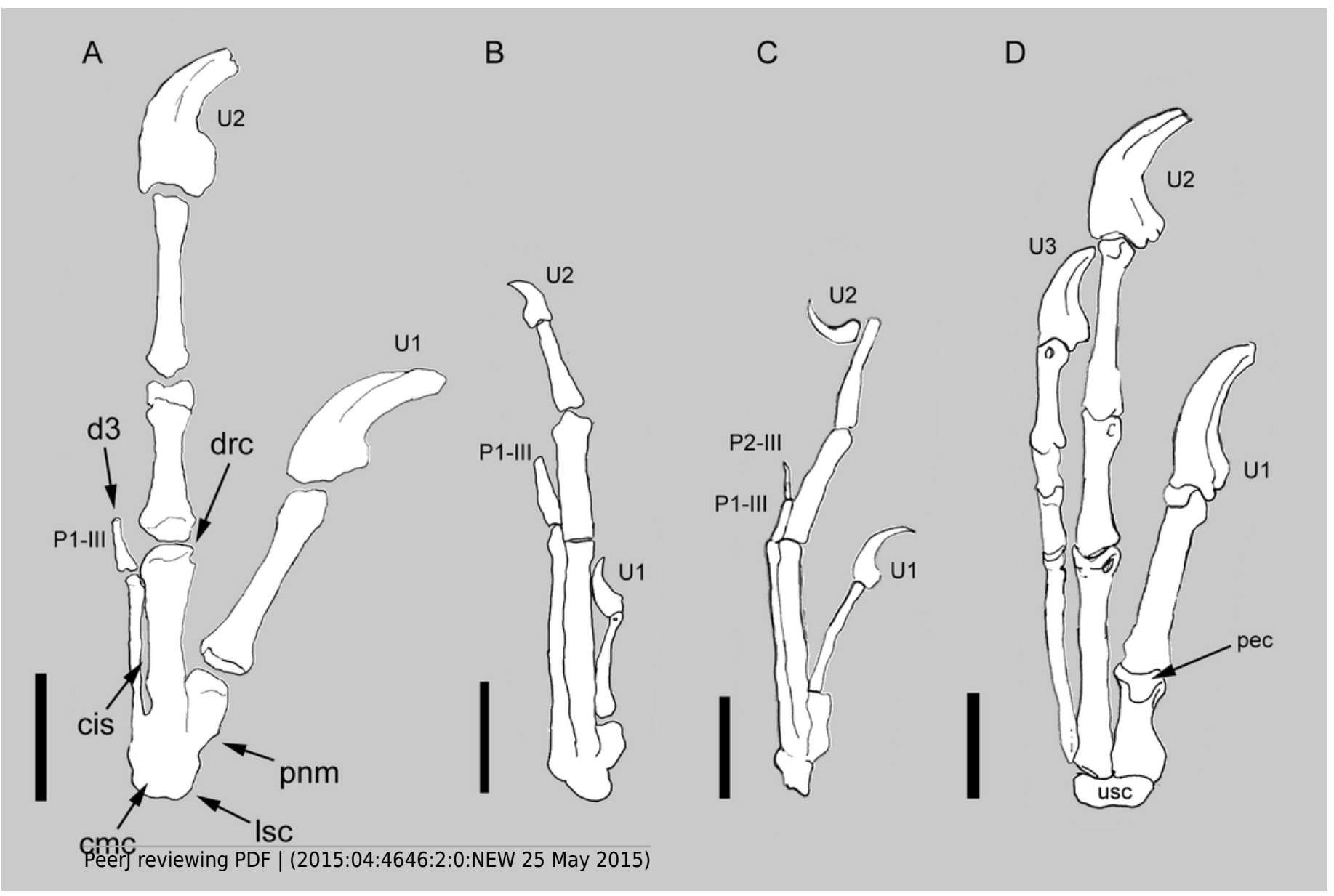




\section{3}

Comparison between the pelvis of Balaur and other paravians.

Pelvis of Balaur in lateral view (A). Comparison of the pubes of Balaur in anteroventral view (B) to those of the pygostylian Sapeornis in anterior view (C), and the dromaeosaurid Velociraptor in posterior view (D). (C) after Zhou and Zhang (2003, fig. 8); (D) after Norell and Makovicky (1999, fig. 19). Scale bar: $10 \mathrm{~mm}$ (A, B, D), 2 mm (C). Abbreviations: aa, antitrochanter; ac, acetabulum; cf, cuppedicus fossa; dfi, dorsal flange of ischium; ipf, interpubic fenestra; is, ischium; pa, pubic apron; ps, pubic symphysis; pu, pubis, sv, sacral vertebrae. 


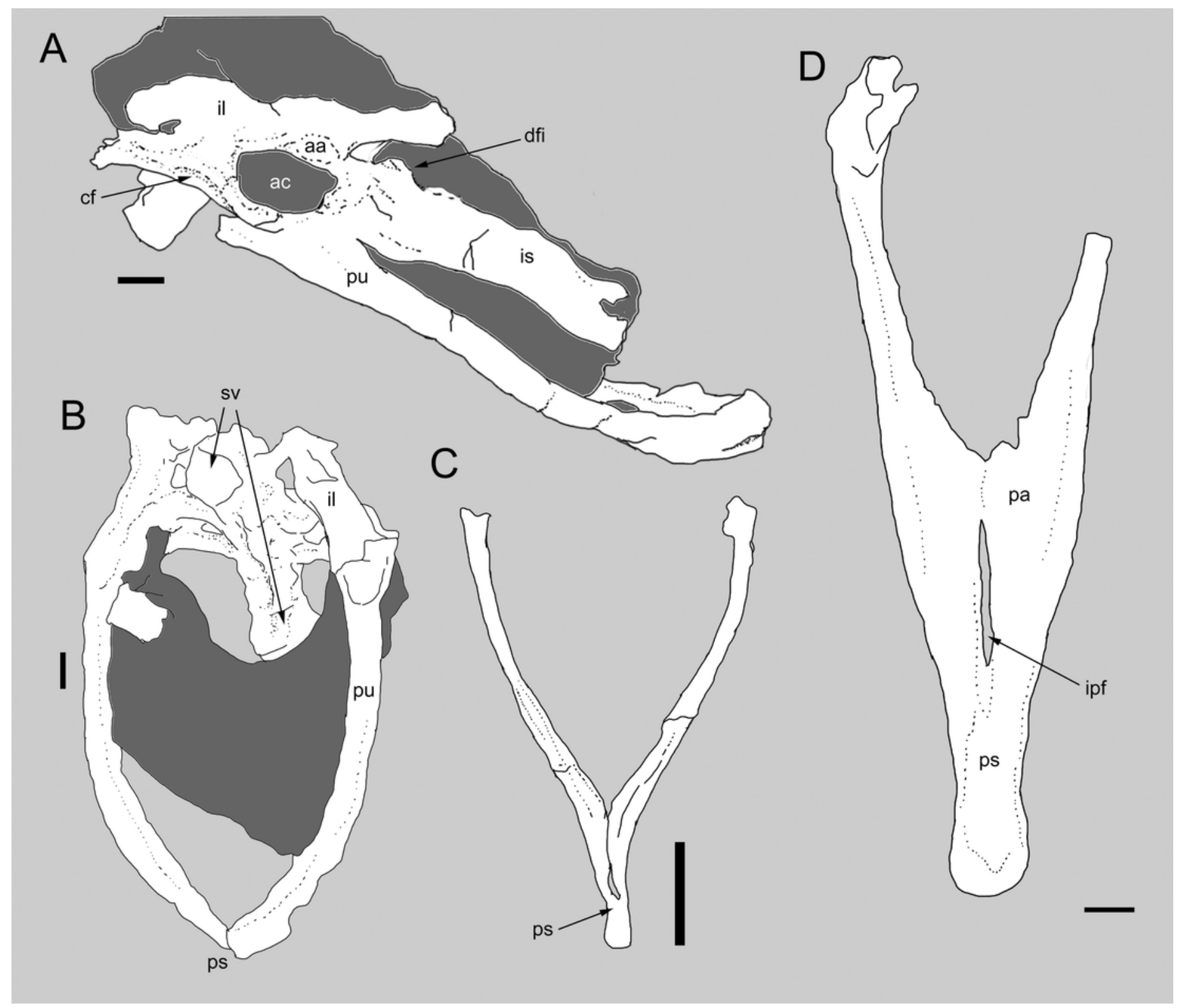


4

Comparison between the metatarsus of Balaur and other paravians.

Comparison of the metatarsus and pes of $(B)$ Balaur to that of $(A)$ the dromaeosaurid Velociraptor; and (C) the pygostylian Zhouornis. (a) after Norell and Makovicky (1997 figs. 6); (C) after Zhang et al. (2013, fig. 8, mirrored from original). Scale bar: $20 \mathrm{~mm}$ (A, B); $10 \mathrm{~mm}$ (C). Abbreviations: mt I, metatarsal I; mt V, metatarsal V; tt, tibiotarsus; U II: pedal ungual II; U IV, pedal ungual IV.

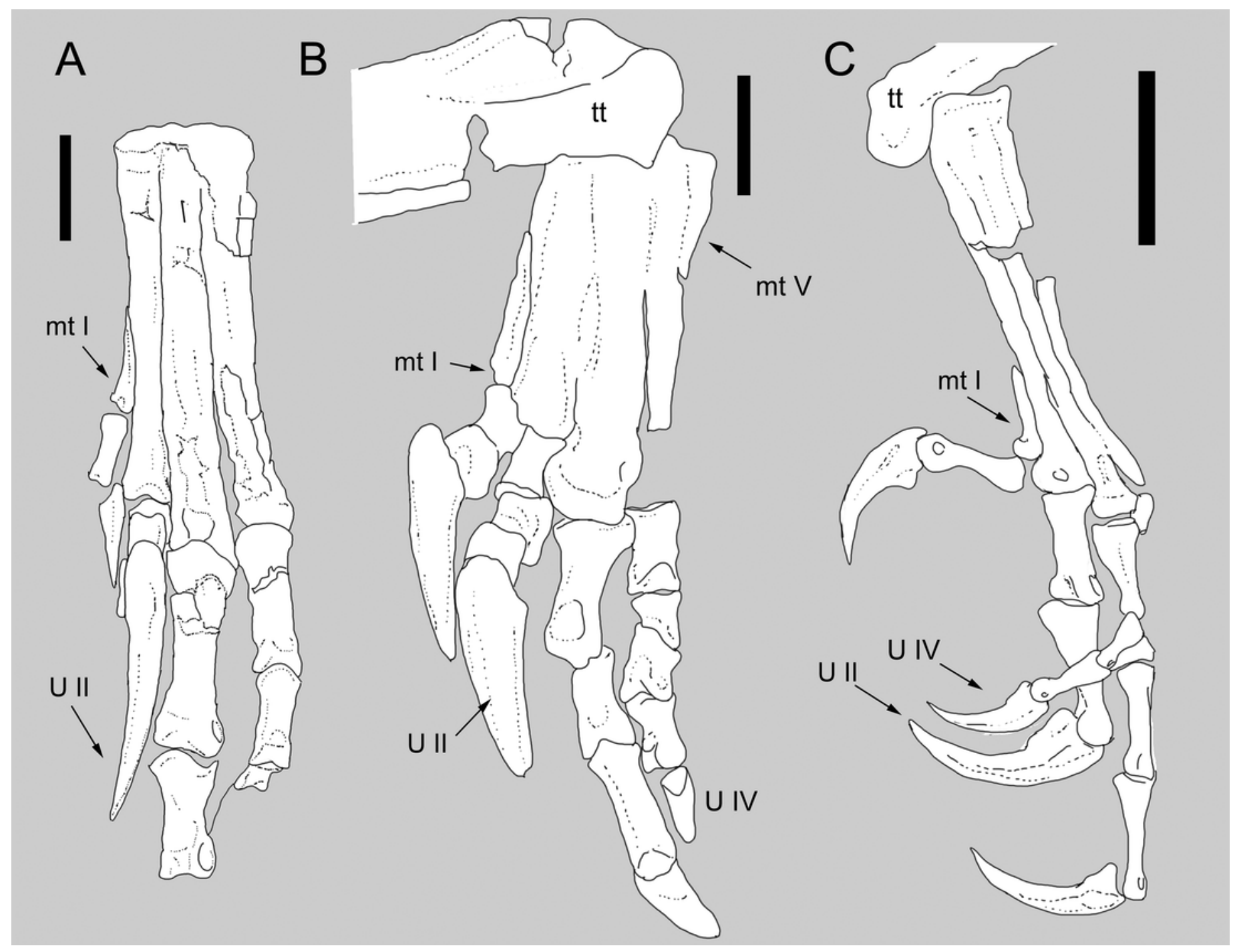




\section{5}

Updated dataset of Brusatte et al. (2014)

Reduced strict consensus of the shortest trees from the analysis of the modified Brusatte et al. (2014) matrix after pruning the 'wildcard' taxa Epidendrosaurus, Hesperonychus, Kinnareemimus, Pedopenna, Pyroraptor, and Shanag. Numbers adjacent to nodes indicate Decay Index values $>1$. 


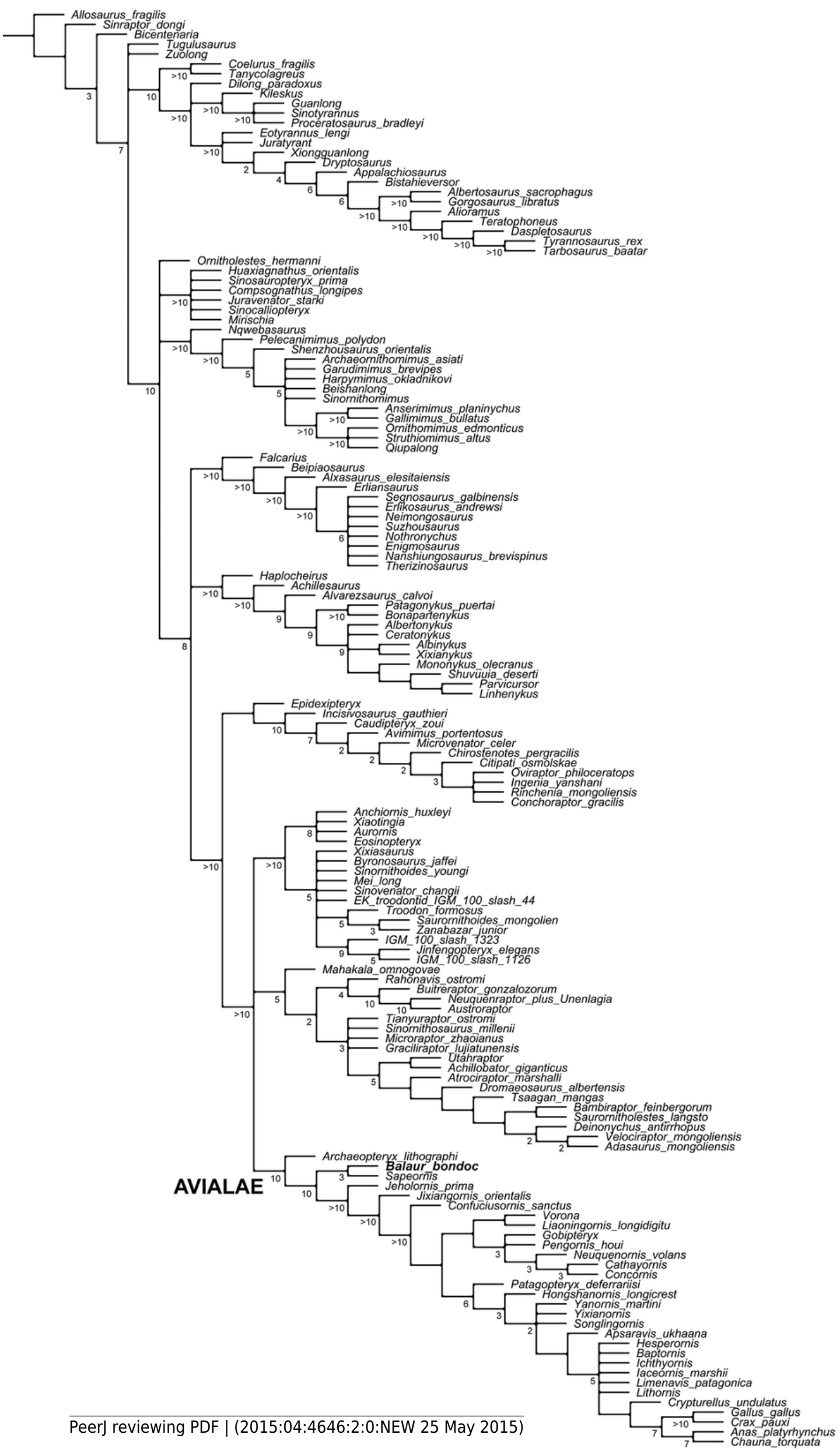


6

Updated dataset of Lee et al. (2014) 


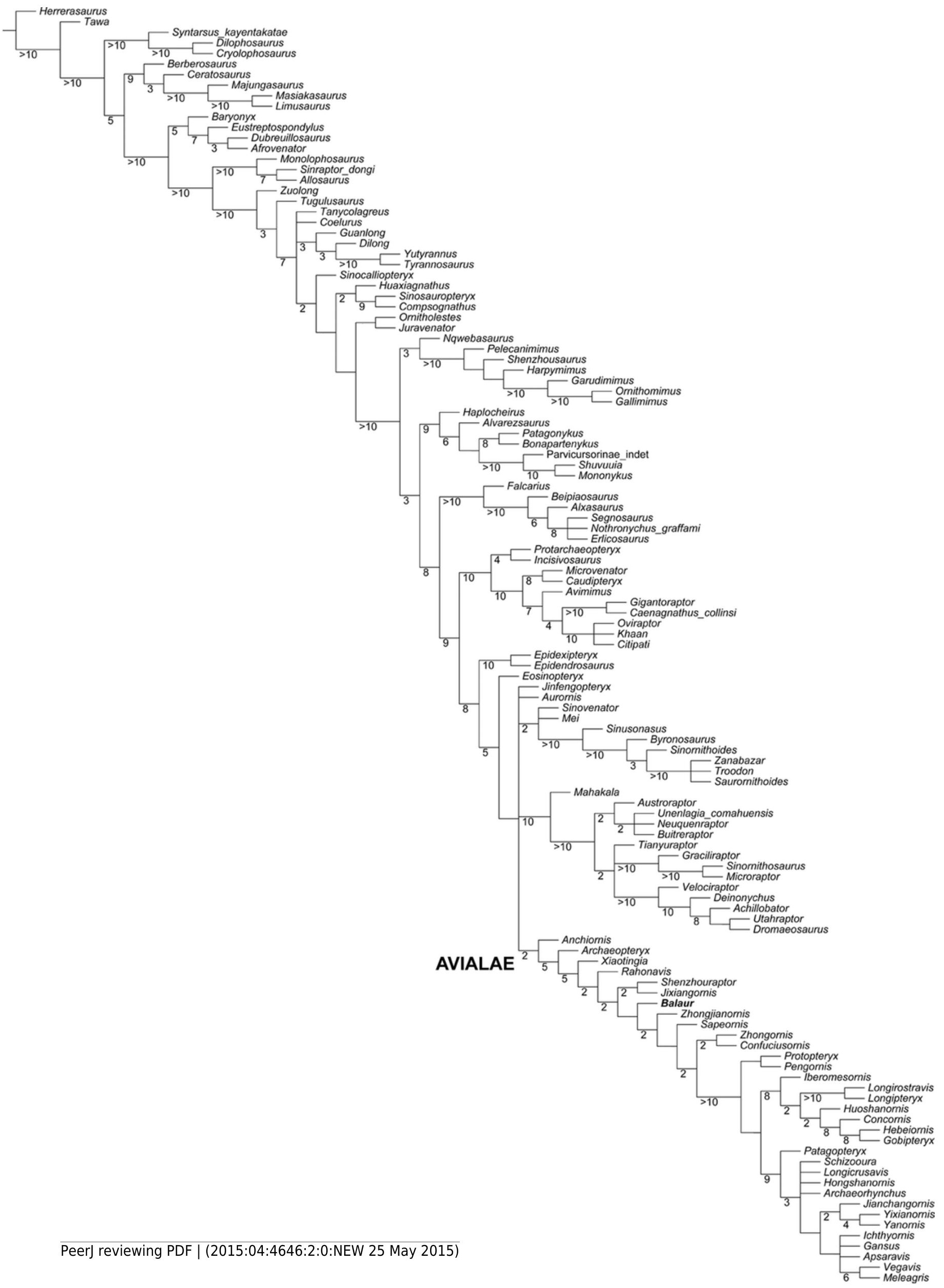




\section{7}

Skeletal reconstruction of Balaur.

Speculative skeletal reconstruction for Balaur bondoc, showing known elements in white and unknown elements in grey. Note that the integument would presumably have substantially altered the outline of the animal in life. Produced by Jaime Headden, used with permission.

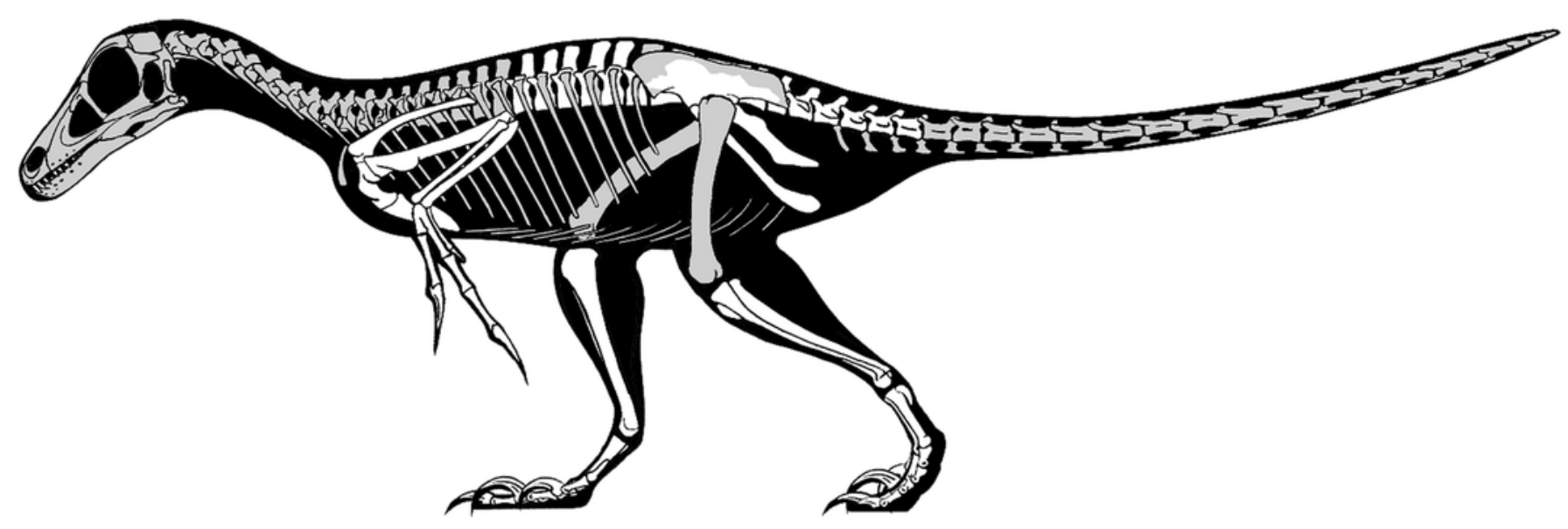

